\title{
Joint inversion of strain and tilt data using the Akaike's Bayesian information criterion to map detailed slip distributions of short-term slow slip events
}

\author{
Takahiro Tsuyuki ${ }^{*} \mathbb{D}$, Akio Kobayashi ${ }^{1}$, Reiko Kai ${ }^{2}$, Takeshi Kimura ${ }^{3}$ and Satoshi Itaba ${ }^{4}$
}

\begin{abstract}
Along the Nankai Trough subduction zone, southwest Japan, short-term slow slip events (SSEs) are commonly detected in strain and tilt records. These observational data have been used in rectangular fault models with uniform slip to analyze SSEs; however, the assumption of uniform slip precludes the possibility of mapping the slip distribution in detail. We report here an inversion method, based on the joint use of strain and tilt data and evaluated in terms of the Akaike's Bayesian information criterion (ABIC), to estimate the slip distributions of short-term SSEs on the plate interface. Tests of this method yield slip distributions with smaller errors than are possible with the use of strain or tilt data alone. This method provides detailed spatial slip distributions of short-term SSEs including probability estimates, enabling improved monitoring of their locations and amounts of slip.
\end{abstract}

Keywords: Nankai Trough, Short-term slow slip event (SSE), Slip distribution, Joint inversion, Strain data, Tilt data

\section{Introduction}

Several types of slow earthquakes commonly occur along the Nankai Trough subduction zone (Fig. 1) of the Philippine Sea plate southwest of Japan (Obara and Kato 2016). Among these, short-term slow slip events (SSEs) with durations of several days have been detected from records of borehole strainmeters (Kobayashi et al. 2006) and tiltmeters (Obara et al. 2004; Hirose and Obara 2005). Strain and tilt data have been combined to represent these short-term SSEs on the basis of rectangular fault models with uniform slip (e.g., Itaba et al. 2012). In another approach, Nishimura et al. (2013) detected short-term SSEs from Global Navigation Satellite System (GNSS) data by fitting linear functions with and without offsets and estimated fault model parameters. Because these estimates assumed a single rectangular fault model

\footnotetext{
*Correspondence: t.tsuyuki@mri-jma.go.jp

${ }^{1}$ Meteorological Research Institute, 1-1 Nagamine, Tsukuba, Ibaraki, Japan Full list of author information is available at the end of the article
}

with uniform slip and used a least-squares evaluation of error, the spatial distribution of slip may be biased.

Alternatively, Kano and Kato (2020) estimated the detailed cumulative slip distribution of short-term SSEs along the Nankai Trough subduction zone from 2004 to 2009 by stacking GNSS data. Hirose and Kimura (2020) used tilt-offset measurements to estimate slip distributions of short-term SSEs from January 2001 to March 2019 in the Shikoku region and gain insight into the slip budget along the strike direction of the Nankai Trough. Although these estimates of the slip distribution on the plate boundary surface yield more detailed slip locations than rectangular fault models, they employed GNSS or tilt data alone. In this study, we developed a joint inversion of strain and tilt data using the Akaike's Bayesian information criterion (ABIC; Akaike 1980) to estimate detailed slip distributions of short-term SSEs. We report the use of this method to calculate detailed spatial slip 


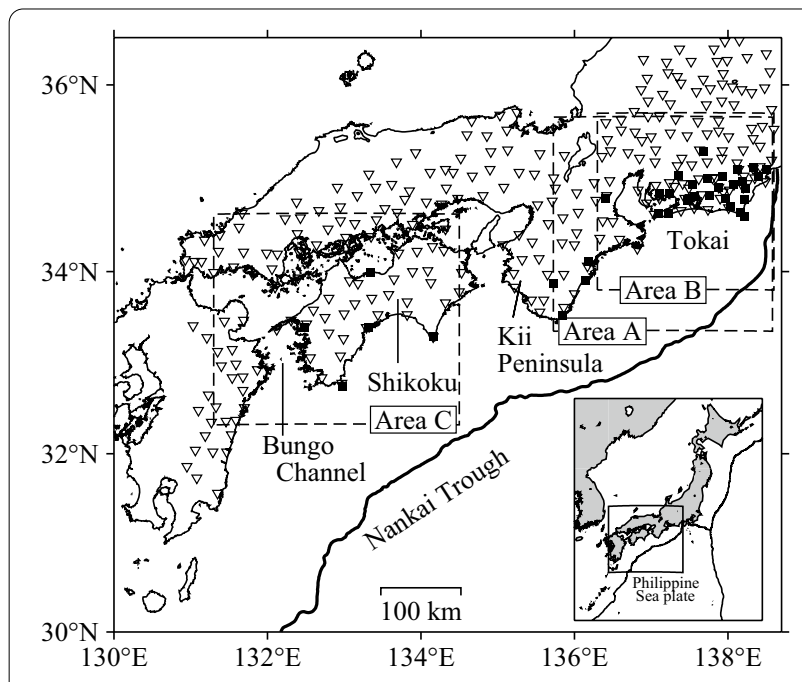

Fig. 1 Map of southwest Japan showing locations of JMA, Shizuoka Prefecture, and AIST strainmeter stations (solid squares) and NIED $\mathrm{Hi}$-net tiltmeter stations (open triangles). The inset map shows the regional location and plate boundaries. Labeled rectangles indicate the areas of other figures

distributions of short-term SSEs and evaluate the error of the obtained slip distributions.

\section{Method}

\section{Inversion of slip distribution}

We represent the observation vector as $\mathbf{o}=\left(\mathrm{o}_{1}, \ldots, \mathrm{o}_{N}\right)^{T}$, where $N$ is the number of observational data components, in this case strain and tilt steps, and $(\ldots)^{T}$ denotes the transpose of the matrix. We seek to determine the slip distribution assuming that the changing trends in strain and tilt data are caused by non-uniform slip on the plate interface. For this purpose, the plate interface is divided into $M$ grid points, and we assume a small subfault centered on each point that has a rectangular shape and uniform slip. By decomposing the fault slip of the $i$ th grid point into two orthogonal directions $\mathrm{s}_{i}$ and $\mathrm{s}_{i+M}$, the slip vector is represented as $\mathbf{s}=\left(\mathrm{s}_{1}, \ldots, \mathrm{s}_{M}, \mathbf{s}_{1+M}, \ldots, \mathrm{s}_{2 M}\right)^{T}$. We divide the observation vector $\mathbf{o}$ into tilt data component $\mathbf{o}_{1}$ and strain data component $\mathbf{o}_{2}$, and then represent the observation vector as

$$
\left(\begin{array}{l}
\mathbf{o}_{1} \\
\mathbf{o}_{2}
\end{array}\right)=\mathbf{G s}+\left(\begin{array}{l}
\mathbf{e}_{1} \\
\mathbf{e}_{2}
\end{array}\right),
$$

where $\mathbf{G}$ is a Green's function coefficient matrix of dimensions $N$ by $2 M$ when a uniform unit slip is given to the small subfault at each grid point. The matrix components can be obtained from surface deformation due to a fault slip in a homogeneous elastic half-space, computed by the method of Okada (1992). $\mathbf{e}_{1}$ and $\mathbf{e}_{2}$ are error vectors of tilt and strain data, respectively. It is assumed that $\mathbf{e}_{1}$ and $\mathbf{e}_{2}$ follow a normal distribution with 0 mean and variance-covariance matrix $\sigma_{1}^{2} \mathbf{E}_{1}$ and $\sigma_{2}^{2} \mathbf{E}_{2}$, respectively. $\sigma_{1}^{2}$ and $\sigma_{2}^{2}$ are scale factors for the variance of $\mathbf{e}_{1}$ and $\mathbf{e}_{2}$. No correlation is assumed between components, and the covariance elements in the variance-covariance matrix are set at 0 . It is not appropriate to use the same scale factor for the variance of different observation data. Therefore, we introduce the hyper-parameter $\eta^{2}\left(=\sigma_{2}^{2} / \sigma_{1}^{2}\right)$ to evaluate errors on different forms of observational data. This hyper-parameter $\eta^{2}$ expresses the relative weight of the strain and tilt datasets in the probability distribution (Funning et al. 2014). Then, the probability density function of the observation vector given a slip distribution $\mathbf{s}$ is represented as

$p\left(\mathbf{o} \mid \mathbf{s} ; \sigma_{1}^{2}, \eta^{2}\right)=\left(2 \pi \sigma_{1}^{2}\right)^{-N / 2}\|\mathbf{E}\|^{-1 / 2} \exp \left[-\frac{1}{2 \sigma_{1}^{2}}(\mathbf{o}-\mathbf{G s})^{T} \mathbf{E}^{-1}(\mathbf{o}-\mathbf{G s})\right]$,

where matrix $\mathbf{E}$ is a function of $\eta^{2}=\sigma_{2}^{2} / \sigma_{1}^{2}$,

$$
\mathbf{E}\left(\eta^{2}\right)=\left[\begin{array}{cc}
\mathbf{E}_{1} & 0 \\
0 & \eta^{2} \mathbf{E}_{2}
\end{array}\right]
$$

which is an $N$ by $N$ dimension matrix, and $\|\ldots\|$ represents the determinant of the matrix.

We represent a slip vector $\mathbf{s}$ using a basis function

$$
\mathbf{s}=\sum_{i}^{2 M} s_{i} X_{i}(x, y),
$$

in which the basis function is the boxcar function

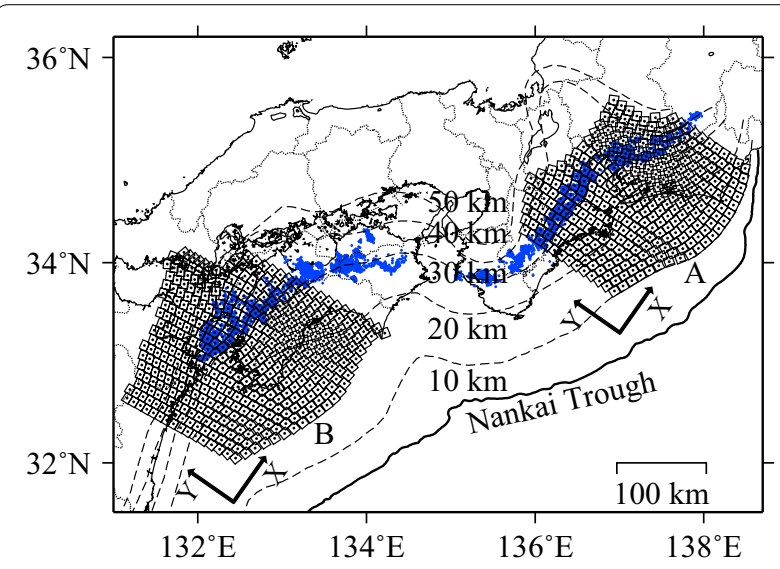

Fig. 2 Set of subfaults (rectangles) and grid points (black dots) used for the inversion analyses. Each grid point is at the center of a rectangle defining a small subfault on the plate interface. The dashed contours indicate the depth of the subducting Philippine Sea plate interface north of the Nankai Trough. Blue dots indicate the hypocenters of deep low-frequency tremors during 2015-2018 (NIED catalog) 

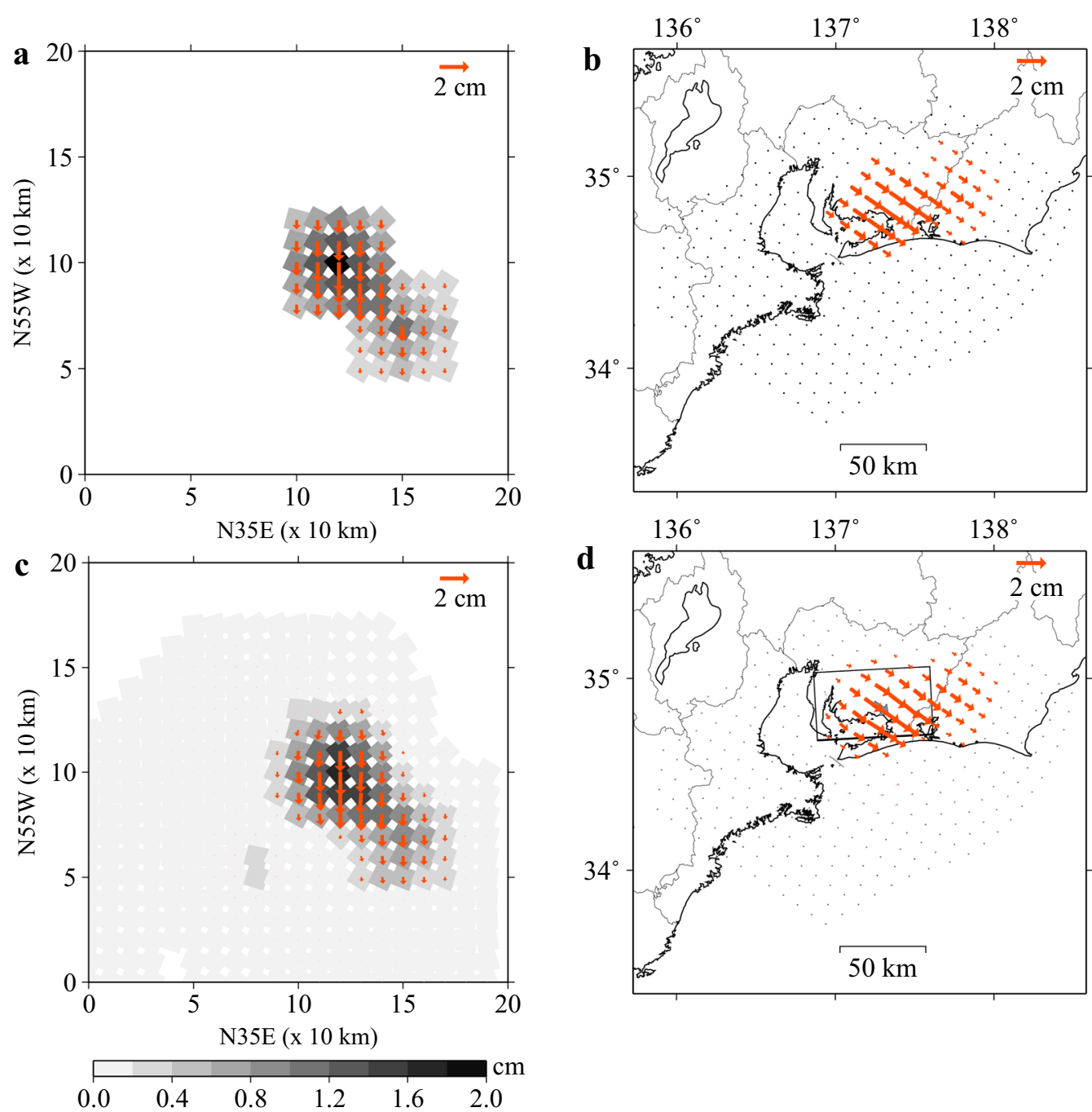

e $1 \sigma$ (N170E slip)
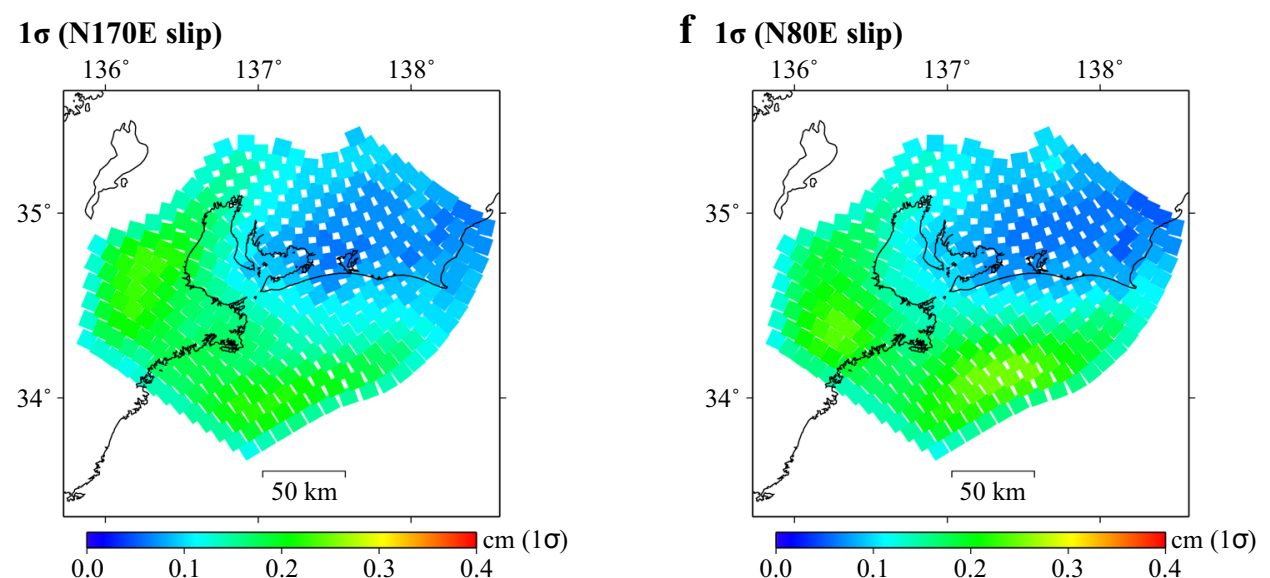

Fig. 3 Test of the proposed method using synthetic strain and tilt datasets. a Given slip distribution. $\mathbf{b}$ Surface projection of the given slip distribution. Dots indicate the location of subfaults. c Retrieved slip distribution. $\mathbf{d}$ Surface projection of the retrieved slip distribution (arrows) and a rectangular fault model (rectangle and gray arrow). Slips exceeding the standard deviation $(1 \sigma)$ are shown in red and slips below the $1 \sigma$ are shown in light pink. Map region corresponds to Area A in Fig. 1. e, f Distribution of the standard deviation (10) of the estimated slip in the direction of N170E (e) and N80E (f) at each subfault 


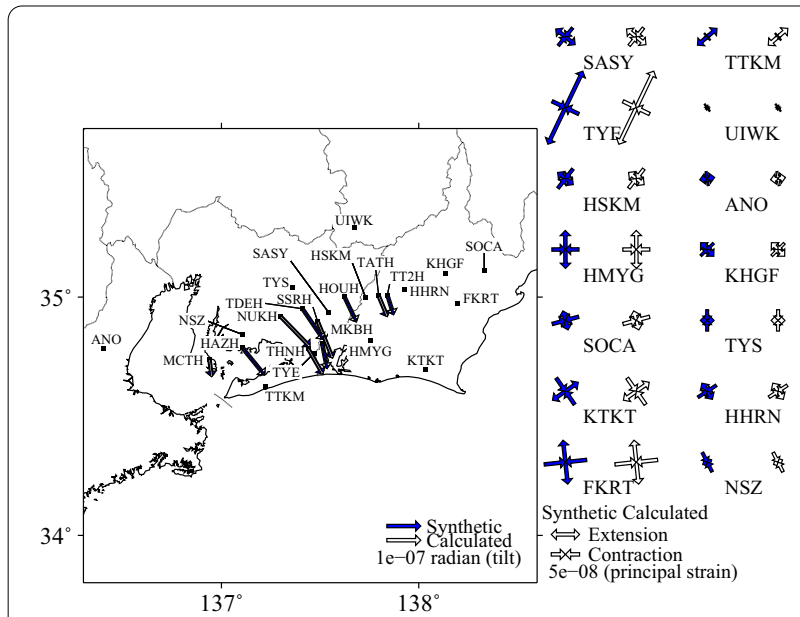

Fig. 4 Horizontal principal strain (arrows in the right panel) and tilt vectors (arrows pointed toward uplift) calculated from the given slip (Synthetic: blue symbols) and the retrieved slip (Calculated: white) shown in Fig. 3c, d. Map region corresponds to Area B in Fig. 1

$$
X_{i}(x, y)=\left\{\begin{array}{l}
1(x, y) \in i \text { th subfault } \\
0(x, y) \notin i \text { th subfault }
\end{array} .\right.
$$

The slip distribution $\mathbf{s}$ is a smooth distribution represented by the $2 M$ by $2 M$ matrix $\mathbf{L}$ and $2 M$-dimension vector $\delta$ as (Fukuda and Johnson 2008)

$$
\mathbf{L s}=\delta
$$

where $\mathbf{L}$ represents a discrete Laplacian and $\delta$ follows a normal distribution with 0 mean and the variancecovariance matrix $\rho^{2} \mathbf{I}$ (where $\mathbf{I}$ is the unit matrix). The resulting slip distribution also follows a normal distribution with 0 mean and variance-covariance matrix $\mathbf{L}^{-1} \rho^{2}\left(\mathbf{L}^{-1}\right)^{T}$, and the probability density function of $\mathbf{s}$ is written as follows with $\mathbf{R}=\mathbf{L}^{T} \mathbf{L}$ :

$$
p\left(\mathbf{s} \mid \rho^{2}\right)=\left(2 \pi \rho^{2}\right)^{-M}\|\mathbf{R}\|^{1 / 2} \exp \left[-\frac{1}{2 \rho^{2}} \mathbf{s}^{\mathrm{T}} \mathbf{R} \mathbf{s}\right] .
$$

According to Bayes' theorem, the probability density function of the slip vector for the observation vector $\mathbf{o}$ is obtained with a normalizing coefficient $\mathrm{c}$ to set the probability to 1 as

$$
p\left(\mathbf{s} \mid \mathbf{o} ; \sigma_{1}^{2}, \eta^{2}, \rho^{2}\right)=\operatorname{cp}\left(\mathbf{o} \mid \mathbf{s} ; \sigma_{1}^{2}, \eta^{2}\right) \mathrm{p}\left(\mathbf{s} \mid \rho^{2}\right) .
$$

With $\alpha^{2}=\sigma_{1}^{2} / \rho^{2}$,

$$
\begin{aligned}
& p\left(\mathbf{s} \mid \mathbf{o} ; \sigma_{1}^{2}, \eta^{2}, \alpha^{2}\right) \\
& =\left(2 \pi \sigma_{1}^{2}\right)^{-(N+2 M) / 2}\left(\alpha^{2}\right)^{M} \\
& \|\mathbf{E}\|^{-1 / 2}\|\mathbf{R}\|^{1 / 2} \exp \left[-\frac{1}{2 \sigma_{1}^{2}} \mathrm{~s}(\mathbf{s})\right] .
\end{aligned}
$$

where

$$
s(\mathbf{s})=(\mathbf{o}-\mathbf{G s})^{T} \mathbf{E}^{-1}(\mathbf{o}-\mathbf{G s})+\alpha^{2} \mathbf{s}^{T} \mathbf{R} \mathbf{s} .
$$

Following Yabuki and Matsu'ura (1992), to find the slip vector $\mathbf{s}$ and hyper-parameters $\sigma_{1}^{2}, \eta^{2}$, and $\alpha^{2}$ to maximize this probability function, first, we hold fixed the three hyper-parameters. Then, the probability density is maximized when the slip vector $\mathbf{s}$ is

$$
\mathbf{s}^{*}=\left(\mathbf{G}^{T} \mathbf{E}^{-1} \mathbf{G}+\alpha^{2} \mathbf{R}\right)^{-1} \mathbf{G}^{T} \mathbf{E}^{-1} \mathbf{o} .
$$

With this $\mathbf{s}^{*}$ and $s\left(\mathbf{s}^{*}\right)$, we can write

$$
s(\mathbf{s})=s\left(\mathbf{s}^{*}\right)+\left(\mathbf{s}-\mathbf{s}^{*}\right)^{T}\left(\mathbf{G}^{T} \mathbf{E}^{-1} \mathbf{G}+\alpha^{2} \mathbf{R}\right)\left(\mathbf{s}-\mathbf{s}^{*}\right) .
$$

Table 1 Optimal hyper-parameters for each case

\begin{tabular}{lrlll}
\hline Case & \multicolumn{1}{c}{ ABIC } & $\boldsymbol{\alpha}^{\mathbf{2}}$ & $\boldsymbol{\sigma}_{\mathbf{1}}^{\mathbf{2}}$ & $\boldsymbol{\eta}^{\mathbf{2}}$ (strain/tilt) \\
\hline Synthetic data & -445.38 & $4.16 \times 10^{-15}$ & $5.08 \times 10^{-20}$ & 0.92 \\
Example 1: 14-19 April 2015 & 2.45 & $1.26 \times 10^{-10}$ & $1.80 \times 10^{-15}$ & 0.38 \\
Based on stain data alone & 229.32 & $3.40 \times 10^{-12}$ & $1.01 \times 10^{-16}$ & - \\
Based on tilt data alone & 420.14 & $8.11 \times 10^{-11}$ & $2.16 \times 10^{-15}$ & - \\
Example 2: 29 December 2015 to 1 January & -336.63 & $4.35 \times 10^{-11}$ & $6.23 \times 10^{-17}$ & 0.10 \\
2016 & & & & $2.20 \times 10^{-16}$ \\
Example 2: 1-5 January 2016 & -284.53 & $1.64 \times 10^{-11}$ & $1.10 \times 10^{-16}$ & 0.25 \\
Example 2: 5-7 January 2016 & -320.50 & $4.81 \times 10^{-11}$ & $8.01 \times 10^{-16}$ & 0.91 \\
Example 3: 23-27 October 2016 & 547.83 & $6.85 \times 10^{-11}$ & $1.33 \times 10^{-15}$ & -.46 \\
Based on stain data alone*1 & 780.51 & $8.74 \times 10^{-10}$ & $5.73 \times 10^{-16}$ & - \\
Based on tilt data alone*1 & 702.08 & $1.82 \times 10^{-11}$ &
\end{tabular}




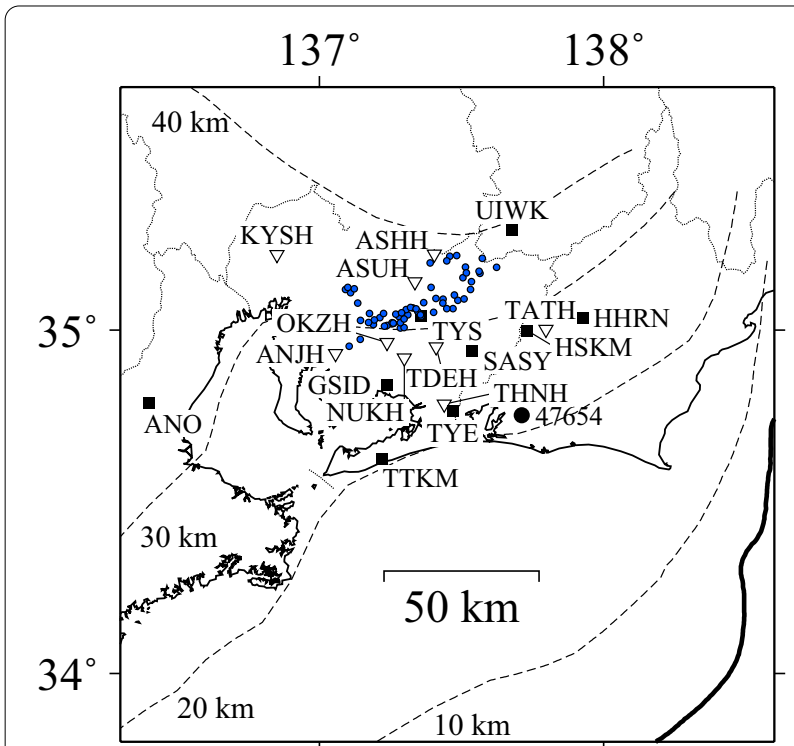

Fig. 5 Epicentral distribution of LFTs (dots) observed in the Tokai region during 14-19 April 2015 (NIED catalog). Also shown are locations of strain observation stations (squares), Hi-net (tilt data) stations (triangles), and Hamamatsu weather station 47654 (circle) Map region corresponds to Area B in Fig. 1. The solid line indicates the Nankai Trough and dashed contours indicate the depth of the Philippine Sea plate

From this equation, the slip distribution $\mathbf{s}$ is a normal distribution with a mean of $\mathbf{s}^{*}$ and covariance $\sigma_{1}^{2}\left(\mathbf{G}^{T} \mathbf{E}^{-1} \mathbf{G}+\alpha^{2} \mathbf{R}\right)^{-1}$.

Next, with the marginal likelihood of $\sigma_{1}^{2}, \eta^{2}$, and $\alpha^{2}$ when a slip distribution is given

$$
\begin{gathered}
P\left(\sigma_{1}^{2}, \alpha^{2}, \eta^{2}\right)=\left(2 \pi \sigma_{1}^{2}\right)^{-N / 2}\left(\alpha^{2}\right)^{M}\left\|\mathbf{E}\left(\eta^{2}\right)\right\|^{-1 / 2}\|\mathbf{R}\|^{1 / 2} \\
\left\|\mathbf{G}^{T} \mathbf{E}\left(\eta^{2}\right)^{-1} \mathbf{G}+\alpha^{2} \mathbf{R}\right\|^{-1 / 2} \exp \left[-\frac{1}{2 \sigma^{2}} \mathrm{~s}(\mathbf{s})\right] .
\end{gathered}
$$

We then use the ABIC (Akaike 1980), which is to be minimized based on the entropy maximization principle (Akaike 1977)

$$
\mathrm{ABIC}=-2 \log \mathrm{P}\left(\sigma_{1}^{2}, \alpha^{2}, \eta^{2}\right) .
$$

To do this requires $\partial P / \partial \sigma_{1}^{2}=0$, which follows:

$$
\sigma_{1}^{2}=\frac{s\left(\mathbf{s}^{*}\right)}{N} .
$$

Substituting this into (14), we obtain where $\mathrm{C}$ is a constant independent of $\alpha^{2}$ and $\eta^{2}$. As we cannot calculate $\alpha^{2}$ and $\eta^{2}$ to minimize ABIC analytically, we determine optimal values $\widehat{\alpha^{2}}$ and $\widehat{\eta^{2}}$ by the shuffled complex evolution (SCE-UA) method (Duan et al. 1992). With these in hand, the optimal value of $\mathbf{s}$ is given as

$$
\widehat{\mathbf{s}}=\left(\mathbf{G}^{T} \mathbf{E}\left(\widehat{\eta^{2}}\right)^{-1} \mathbf{G}+\widehat{\alpha^{2}} \mathbf{R}\right)^{-1} \mathbf{G}^{T} \mathbf{E}\left(\widehat{\eta^{2}}\right)^{-1} \mathbf{o},
$$

the optimal value of $\sigma_{1}^{2}$ is given as.

$$
\widehat{\sigma_{1}^{2}}=\frac{s(\widehat{s})}{N}
$$

and the covariance of the estimated errors of $\widehat{\mathbf{s}}$ is given as

$$
\widehat{\sigma_{1}^{2}}\left(\mathbf{G}^{T} \mathbf{E}^{-1} \mathbf{G}+\widehat{\alpha^{2}} \mathbf{R}\right)^{-1}
$$

\section{Estimation of rectangular fault model parameters}

For the evaluation of the slip-distribution model, we also modeled a short-term SSE as a rectangular fault with parameters

$$
\boldsymbol{\Theta}=(\lambda, \phi, h, L, W, S, \delta, R, D),
$$

where $\lambda$ is the longitude, $\phi$ the latitude, and $h$ the depth of the center of the fault; $L$ is the length, $W$ the width, $S$ the strike, and $\delta$ the dip of the fault; and $R$ is the rake and $D$ the amount of slip. The amount of slip is uniform on the fault in this model. Observation data $\left(\mathbf{o}_{1}, \mathbf{o}_{2}\right)^{T}$ are represented with residual $\mathbf{r}$ as

$$
\left(\mathbf{o}_{1}, \mathbf{o}_{2}\right)^{T}=G D+r,
$$

where the Green's function coefficient matrix $\mathbf{G}$ is calculated by the same method used for the inversion of slip distribution. We estimate parameters of $\Theta$ that minimize L2 norm

$$
\|\mathbf{r}\|^{2} \rightarrow \min .
$$

First, the optimal position $(\lambda, \phi)$ of the fault and the amount of slip $D$ are calculated by a grid search method with the other parameters held fixed, using the upper surface of the subducting plate as the position according to Itaba and Ando (2011). Since we fixed the length and the width of the fault $20 \mathrm{~km}$ in the grid search, strain and tilt are linearly related to the amount of slip. Second, the optimal value of parameter $\boldsymbol{\Theta}$ is calculated to minimize the sum of squares of

$$
\operatorname{ABIC}\left(\alpha^{2}, \eta^{2}\right)=\operatorname{Nlog}\left\{\mathbf{s}\left(\mathbf{s}^{*}\right)\right\}-2 \operatorname{Mlog} \alpha^{2}+\log \left\|\mathbf{E}\left(\eta^{2}\right)\right\|\left\|\mathbf{G}^{\mathrm{T}} \mathbf{E}\left(\eta^{2}\right)^{-1} \mathbf{G}+\alpha^{2} \mathbf{R}\right\|+\mathrm{C},
$$



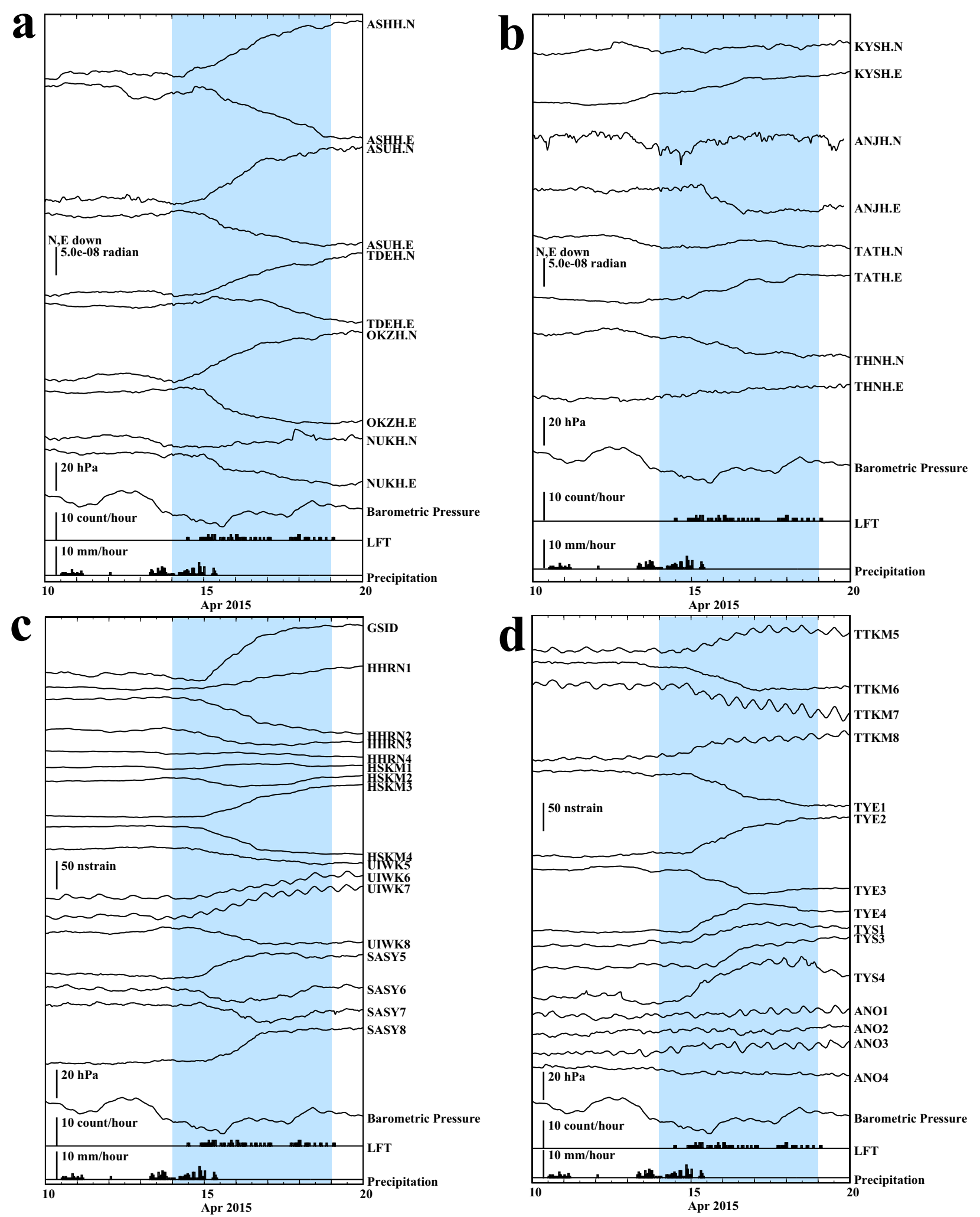

Fig. 6 Time series of $\mathbf{a}, \mathbf{b}$ corrected tilt data and $\mathbf{c}$, $\mathbf{d}$ corrected strain data for 10-19 April 2015. Also shown are numbers of LFTs per hour and barometric pressure and precipitation data from Hamamatsu weather station. Linear trends have been removed from the original strain and tilt data. Data from the period in blue (0000 on 14 April to 0000 on 19 April) were used to estimate slip distribution in this study 

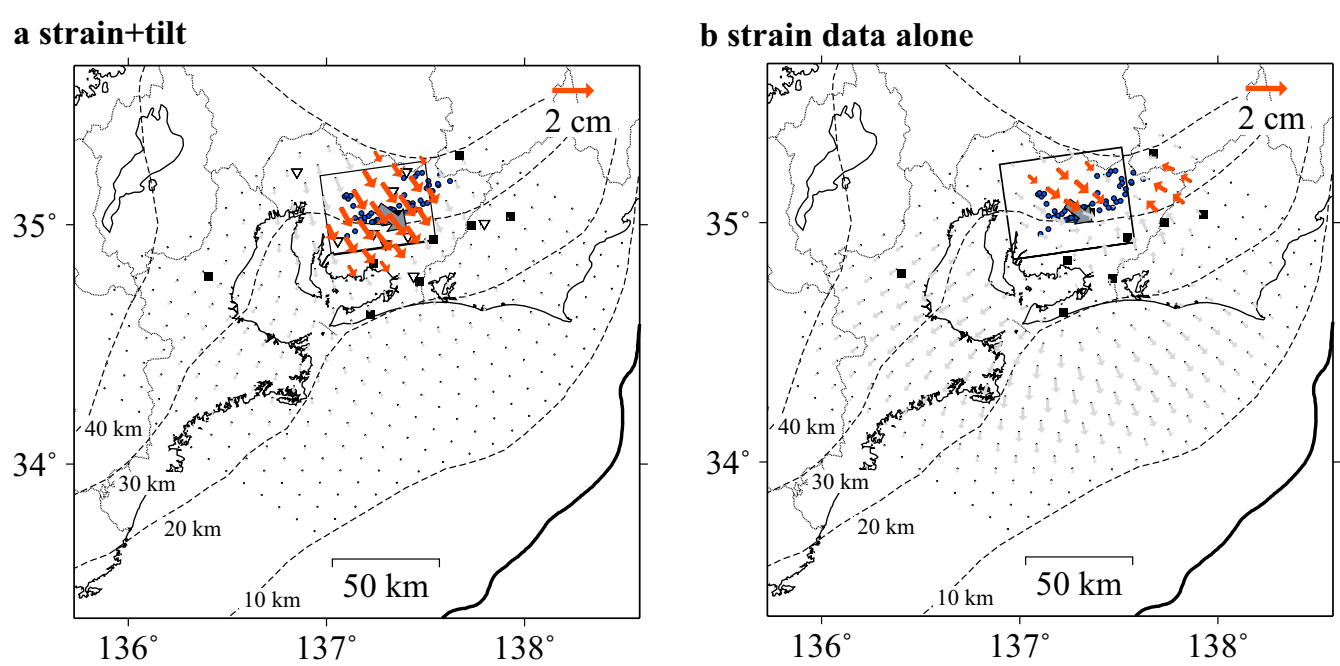

c tilt data alone

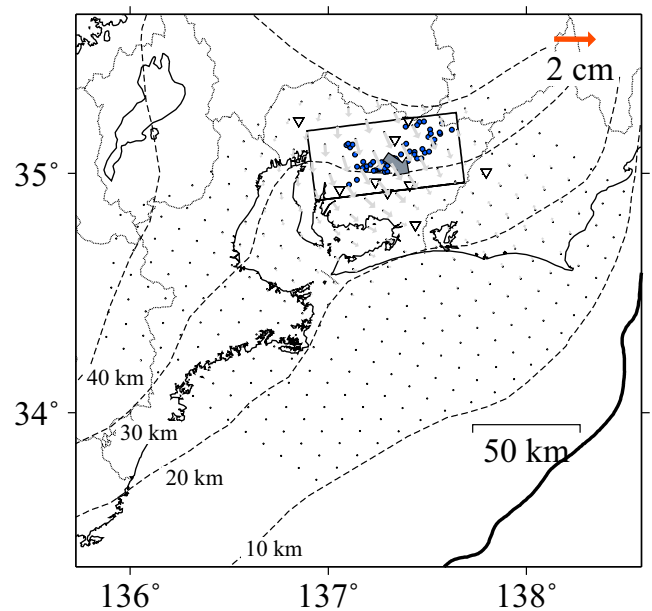

Fig. 7 Estimated slip distributions during 14-19 April 2015. Map region corresponds to Area A in Fig. 1. a Surface projection of estimated slip distribution on the plate interface (arrows) and a rectangular fault model (rectangle and gray arrow). Slips exceeding the standard deviation (1 $\sigma$ ) are shown in red and slips below the $1 \sigma$ are shown in light pink. Colored dots are LFT epicenters during 14-19 April (see Fig. 5). The solid line indicates the Nankai Trough and dashed contours indicate the depth of the Philippine Sea plate. b Surface projection of estimated fault slip on the plate interface and rectangular fault model based on strain data alone. c Surface projection of estimated fault slip on the plate interface and rectangular fault model based on tilt data alone

the residual between theoretical and observed values within a certain search range around the optimal fault position and fault parameter at that position by the SCE-UA method (Duan et al. 1992).

\section{Strain and tilt data}

We used strain observational data from volume strainmeters (Sacks et al. 1971) and multi-component strainmeters (Ishii et al. 2002) of the Japan
Meteorological Agency (JMA), Shizuoka Prefecture, and the National Institute of Advanced Industrial Science and Technology (AIST). We used tilt data from the high-sensitivity accelerometers of the Hi-net (Okada et al. 2004; Obara et al. 2005) stations of the National Research Institute for Earth Science and Disaster Resilience (NIED). The locations of all stations are shown in Fig. 1. We used all components of the multi-component strainmeter measurements. The effects of barometric pressure, tides, precipitation, 
a strain+tilt (N170E slip)

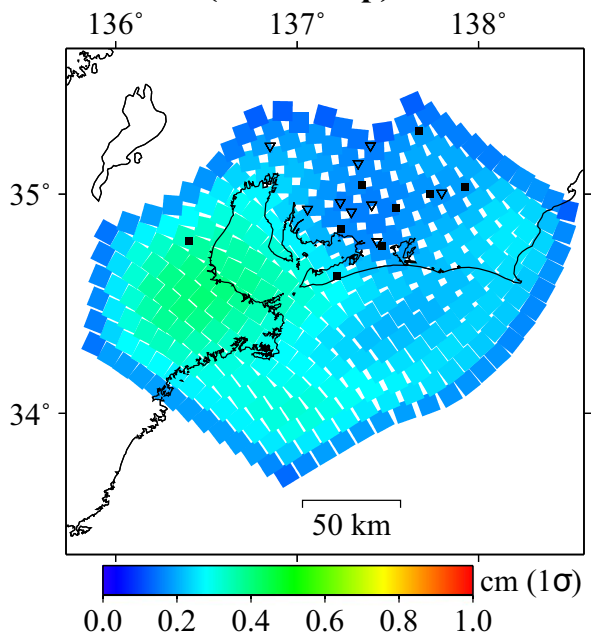

c strain data alone (N170E slip)

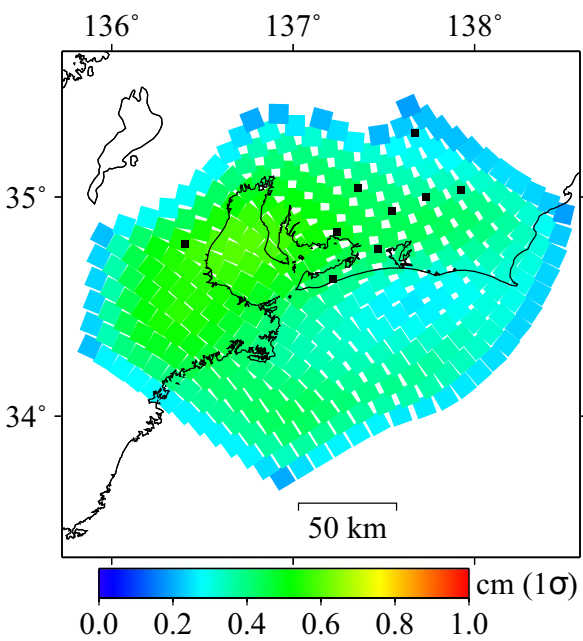

e tilt data alone (N170E slip)

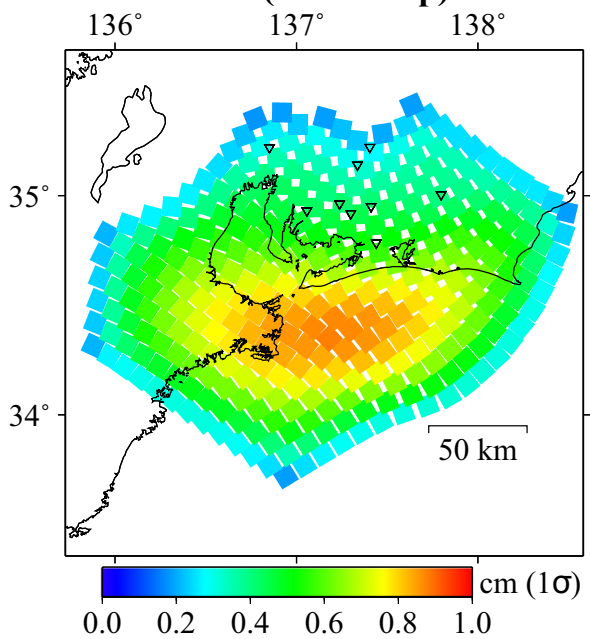

b strain+tilt (N80E slip)

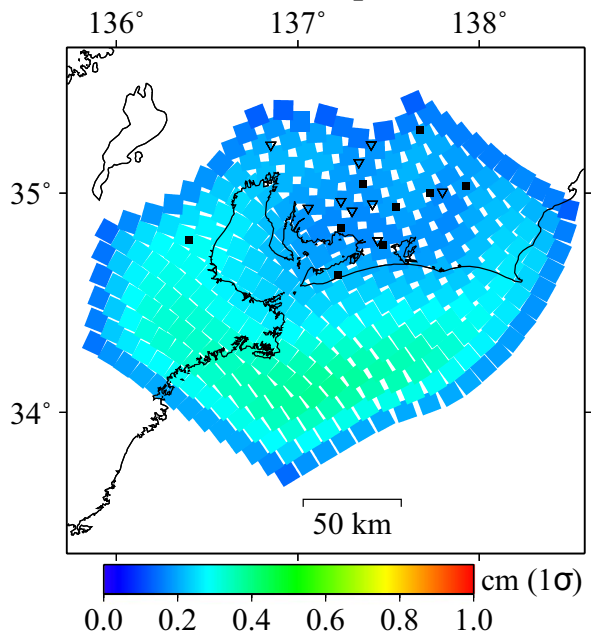

d strain data alone (N80E slip)

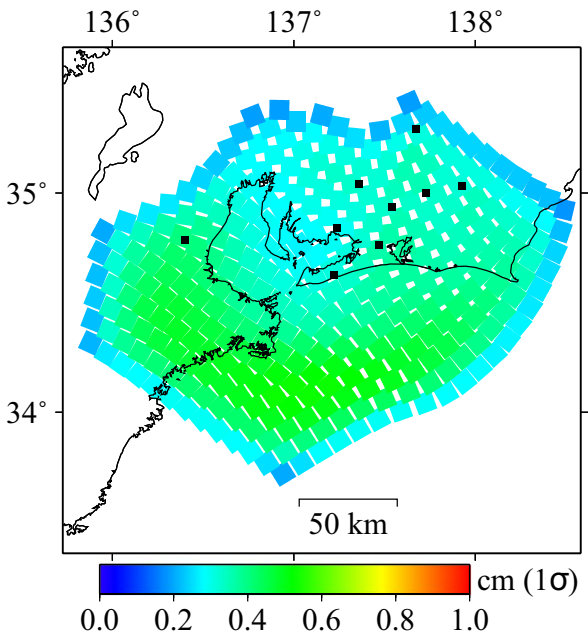

f tilt data alone (N80E slip)

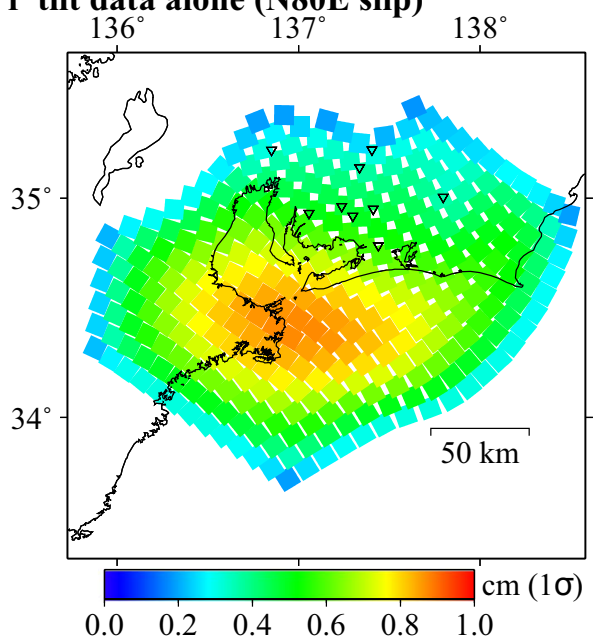

Fig. 8 Distribution of the standard deviation (10) of the estimated slip (Fig. 7) in the N170E direction (left panel) and N80E direction (right panel) at each subfault. Map region corresponds to Area A in Fig. 1. a, b Standard deviation of the estimated slip based on strain and tilt data. c, d Standard deviation of the estimated slip based on strain data alone. e, f Standard deviation of the estimated slip based on tilt data alone 


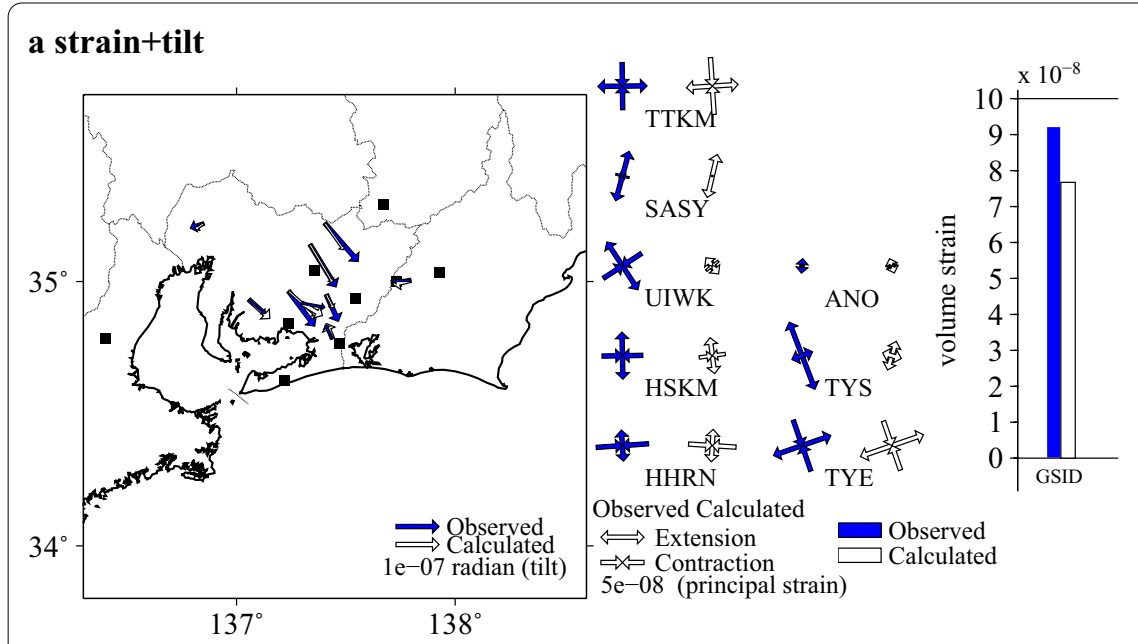

b strain data alone

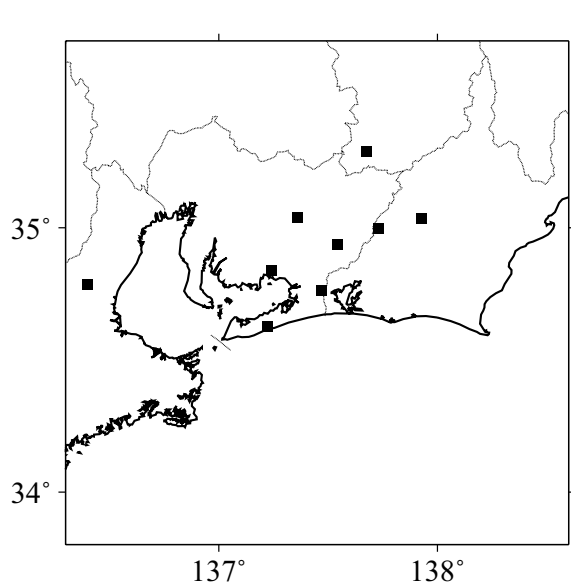

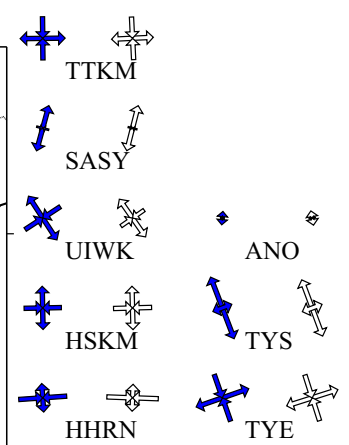

Observed Calculated

$\Longleftrightarrow$ Extension $\Rightarrow x$ Contraction $5 \mathrm{e}-08$ (principal strain)

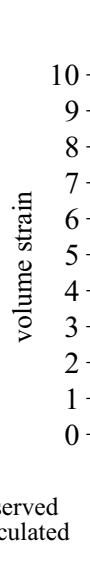

c tilt data alone

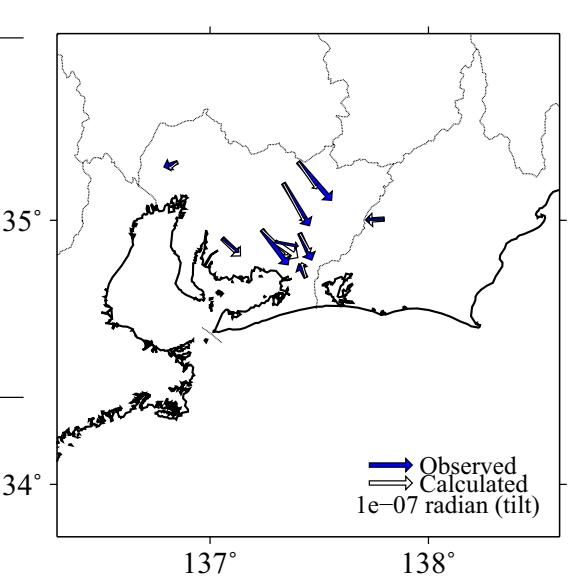

Fig. 9 Observed and calculated strain (right panel) and tilt (left panel) data during 14-19 April 2015. Map region corresponds to Area B in Fig. 1. a Strain data and tilt data from observations (blue) and calculated from the estimated slip distribution shown in Fig. 7a (white). b Strain data from observations (blue) and calculated from the estimated slip distribution shown in Fig. 7b (white). c Tilt data from observations (blue) and calculated from the estimated slip distribution shown in Fig. 7c (white)

and geomagnetism were removed from the 1 - $h$ average strain and tilt values during the period from January 2015 to December 2016 as described below. Background linear trends during a time period before the SSEs were then removed from the corrected data.

Barometric pressure effects were corrected by first-order correlation with data from the barometer attached to the observation station or barometric data from the nearest JMA weather station. Tidal effects were removed from the pressure-corrected data using Baytap-G software (Tamura et al. 1991). Precipitation effects were corrected using a three-stage tank model (Kimura et al. 2015). Because the multi-component strainmeters contain a magnetic sensor, the influence of geomagnetism was removed by the method of Miyaoka (2011). In addition, observed (in-situ) strain data from borehole strainmeters may be amplified or attenuated in response to crustal strain (Gladwin and Hart 1985). This effect was removed by a calibration based on theoretical tides (Matsumoto et al. 2001; Hirose et al. 2019) for multi-component strainmeters and one based on theoretical teleseismic waveforms (e.g., Nakanishi and Kasahara 1990) for volume strainmeters.

\section{Subfaults parameters}

The set of subfaults used for the basis functions introduced in the Method section is shown in Fig. 2. We 
Table 2 Inversion results for each case

\begin{tabular}{llll}
\hline Case & Seismic moment (N m) & Moment magnitude & Standard deviation/slip (cm) \\
\cline { 3 - 3 } & & & N170E \\
\hline Example 1: 14-19 April 2015 & $7.99 \times 10^{17}$ & 5.87 & $0.18 / 1.15$ \\
Rectangle fault model & $1.25 \times 10^{18}$ & 6.00 & $0.43 / 0.56$ \\
Based on strain data alone & $3.20 \times 10^{17}$ & 5.60 & $0.19 / 0.56$ \\
Rectangle fault model & $1.54 \times 10^{18}$ & 6.06 & $0.36 / 0.97$ \\
Based on tilt data alone & - & - & $0.33 / 0.65$ \\
Rectangle fault model & $1.27 \times 10^{18}$ & 6.00 & $0.07 / 0.25$ \\
Example 2: 29 December 2015 to 1 January 2016 & $6.05 \times 10^{17}$ & 5.79 & $0.20 / 0.61$ \\
Rectangle fault model & $3.81 \times 10^{17}$ & 5.65 & $0.40 / 0.26$ \\
Example 2: 1-5 January 2016 & $6.67 \times 10^{17}$ & 5.82 & $0.07 / 0.30$ \\
Rectangle fault model & $6.14 \times 10^{17}$ & 5.79 & $0.07 / 0.36$ \\
Example 2: 5-7 January 2016 & $1.56 \times 10^{17}$ & 5.40 & $0.23 / 0.89$ \\
Rectangle fault model & $4.28 \times 10^{17}$ & 5.69 & $0.16 / 0.86$ \\
Example 3: 23-27 October 2016 & $6.92 \times 10^{17}$ & 5.83 & $0.15 / 0.17$ \\
Rectangle fault model & $1.16 \times 10^{18}$ & 5.98 & $0.07 / 0.15$ \\
Based on strain data alone & $2.05 \times 10^{17}$ & 5.47 & $0.25 / 0.42$ \\
Rectangle fault model & $1.81 \times 10^{18}$ & - & $0.43 / 1.00$ \\
Based on tilt data alone & - & 5.95 & $0.15 / 0.17$ \\
Rectangle fault model & $1.07 \times 10^{18}$ & & $0.46 / 0.22$ \\
\hline
\end{tabular}

a 1 The standard deviation and amount of the slip in the two orthogonal directions (N170E and N80E) at the maximum slip subfault

approximated the area around the Nankai Trough by rectangular coordinates with the $\mathrm{Y}$-axis oriented $\mathrm{N} 55^{\circ} \mathrm{W}$, the direction of subduction of the Philippine Sea plate (Heki and Miyazaki 2001). Grid points were set every $10 \mathrm{~km}$ in the $\mathrm{X}$-axis $\left(\mathrm{N} 35^{\circ} \mathrm{E}\right)$ direction and $10 \mathrm{~km}$ intervals along the plate interface. $\mathrm{X}$ and $\mathrm{Y}$ axes are shown in Fig. 2. We defined a small $10 \mathrm{~km}$ square subfault (rectangular in Fig. 2) centered on each grid points with specified strike and dip according to the configuration of the upper surface of the subducting Philippine Sea plate (Hirose et al. 2008) and used in subsequent analyses. As we represented a slip vector using the boxcar basis function (Eqs. 4, 5), we supposed a uniform slip at each subfaults and calculated the Green's function. It should be mentioned that subfaults have overlaps and gaps on the plate interface in discretization, which can cause errors when calculating the whole slip amount in the region.

\section{Verification of the method using a synthetic dataset}

We checked the validity of our inversion method using a synthetic dataset for the set of subfaults in region A in Fig. 2. The subfaults were assigned the slip distribution shown in Fig. 3a,b, in which the slip amount varies from point to point (every $10 \mathrm{~km}$ ). We calculated synthetic linear strain at 14 measurement points and tilt at 10 measurement points in a homogeneous elastic half-space with a Poisson's ratio of 0.25 using the formula of Okada (1992), yielding the results shown in Fig. 4. Strain changes were converted to the principal strain in this figure. We did not consider the measurement errors. We estimated a slip distribution (Fig. 3c,d) and rectangular fault model parameters separately with this synthetic data set. Since we did not consider the measurement errors, only modeling errors were contained (Yabuki and Matsu'ura 1992) in the errors of Eq. (1). Therefore, in the variancecovariance matrix of observation error, the covariance components were not considered and the variance components were set to 1.0.

Optimal hyper-parameters from this exercise are listed in Table 1. We introduced hyper-parameter $\eta^{2}$ to represent the weight of the strain and tilt dataset. In this test, since the observation data used for the inversion do not include any error, this parameter representing the weights of the strain and tilt data should be 1.0. Therefore, it is reasonable to obtain 0.92 as this value. The slip distribution retrieved by the inversion 


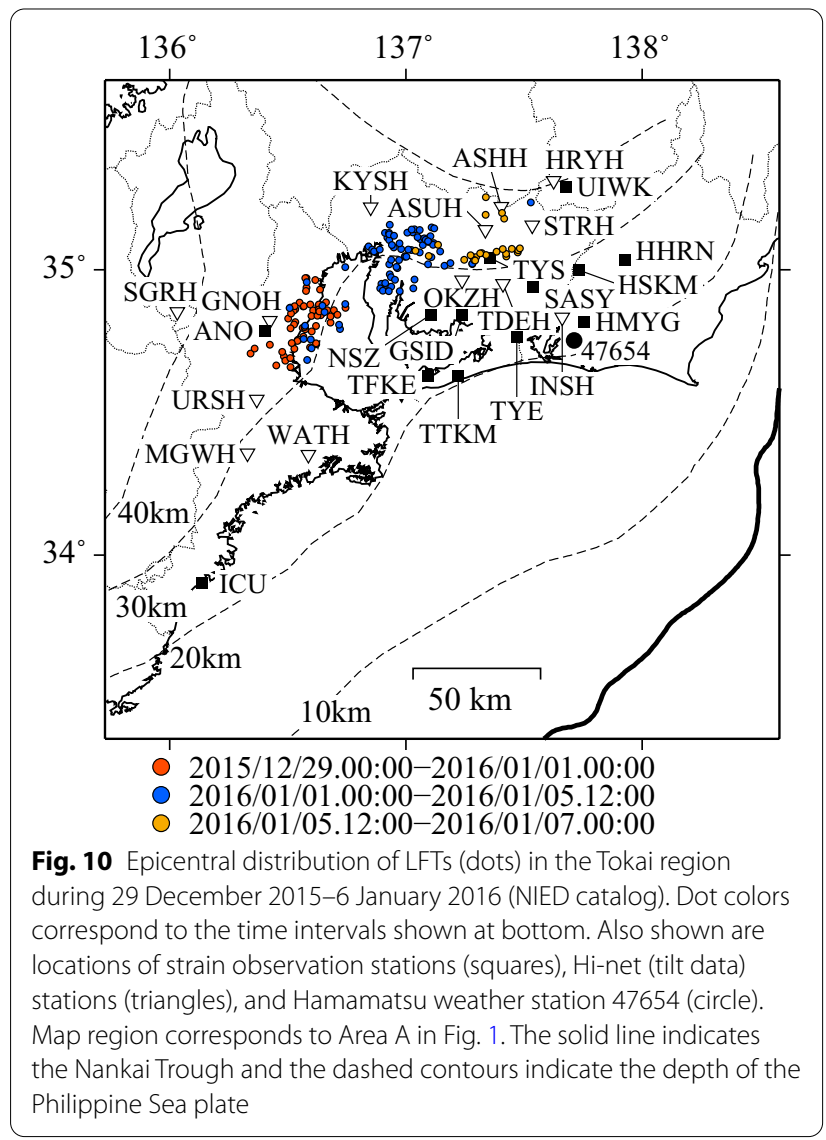

(Fig. 3c, d) nearly matched the given slip distribution (Fig. 3a, b). Distribution of the standard deviation of the estimated slip in the two orthogonal directions at each subfault is shown in Fig. 3e, f. The standard deviation was used as a reference to evaluate the estimation error of slip obtained in each subfault. It can be seen that the standard deviation is relatively small in the region where many observation points are distributed. We calculated the total seismic moment using only subfaults with slips larger than the 1- $\sigma$ estimation error in this study. The calculated total seismic moment of $1.45 \times 10^{18} \mathrm{~N} \mathrm{~m}\left(M_{\mathrm{w}}=6.04\right)$ was almost equal to the given seismic moment of $1.41 \times 10^{18} \mathrm{~N} \mathrm{~m}$ $\left(M_{\mathrm{w}}=6.03\right)$. A rigidity of $4.0 \times 10^{10} \mathrm{~N} \mathrm{~m}^{-2}$ was assumed in this study. Strain and tilt change calculated from the given and the retrieved slip distribution are similar (Fig. 4). We also estimated a rectangular fault model with the same data set. The estimation based on the rectangular fault model (rectangle in Fig. 3d) imperfectly reproduced the given slip and the eastern side of the given slip area is not included in the rectangular fault model. Estimated seismic moment was $1.33 \times 10^{18} \mathrm{~N} \mathrm{~m}\left(M_{\mathrm{w}}=6.02\right)$. Slip on the fault was assumed to be uniform in rectangular fault model, and therefore, the estimated fault model, while including all points with given large slip, excluded some with given small slip. When calculating the average slip amount for a long period, the estimation of the slip distribution at the grids is more appropriate than the rectangular fault.

\section{Results and discussion}

In this section, we analyzed some known short-term SSEs as examples to test our inversion method.

\section{Example 1}

In the first example, we tested whether the simultaneous use of strain and tilt data (joint use) improves the estimation error for a short-term SSE beneath region A in Fig. 2. Figure 5 shows the distribution of low-frequency tremor events (LFTs) in the Tokai area during 14-19 April 2015. We plotted the LFTs taken from the NIED catalog (Maeda and Obara 2009; Obara et al. 2010) in this study. During that time, the strain and tilt change appeared (Fig. 6). These phenomena may correspond to a short-term SSE in this region (e.g., Ochi et al. 2015; Kimura and Kimura 2015). We analyzed the slip distributions resulting from the use of strain or tilt data alone, and analyzed the slip distribution by our inversion method using strain and tilt data. The observational components to be used were selected manually. Observed values are calculated using the difference between the corrected data at the beginning and the end of the period in this study (e.g., Itaba and Ando 2011). The uncertainties of the data are represented by the variance from 11 March to 14 April 2015. (Additional file 1: Table S1). We considered that the error contained in the data was mainly observation error, and that the observation component with larger variation in the original data had larger error. Therefore, in the variance-covariance matrix, the diagonal elements were set to the ratio of each component's variance to their maximum variance for the

(See figure on next page.)

Fig. 11 Time series of $\mathbf{a}, \mathbf{b}$ corrected tilt data and $\mathbf{c}$, $\mathbf{d}$ corrected strain data for 22 December 2015 to 8 January 2016 . Also shown are numbers of LFTs per hour and barometric pressure and precipitation data from Hamamatsu weather station. Linear trends have been removed from the original strain and tilt data. Data from the periods in red (29 December 2015 to 1 January 2016), blue (1 January to 1200 on 5 January 2016 ), and yellow (1200 on 5 January to 7 January) were used to estimate slip distributions in this study 
a

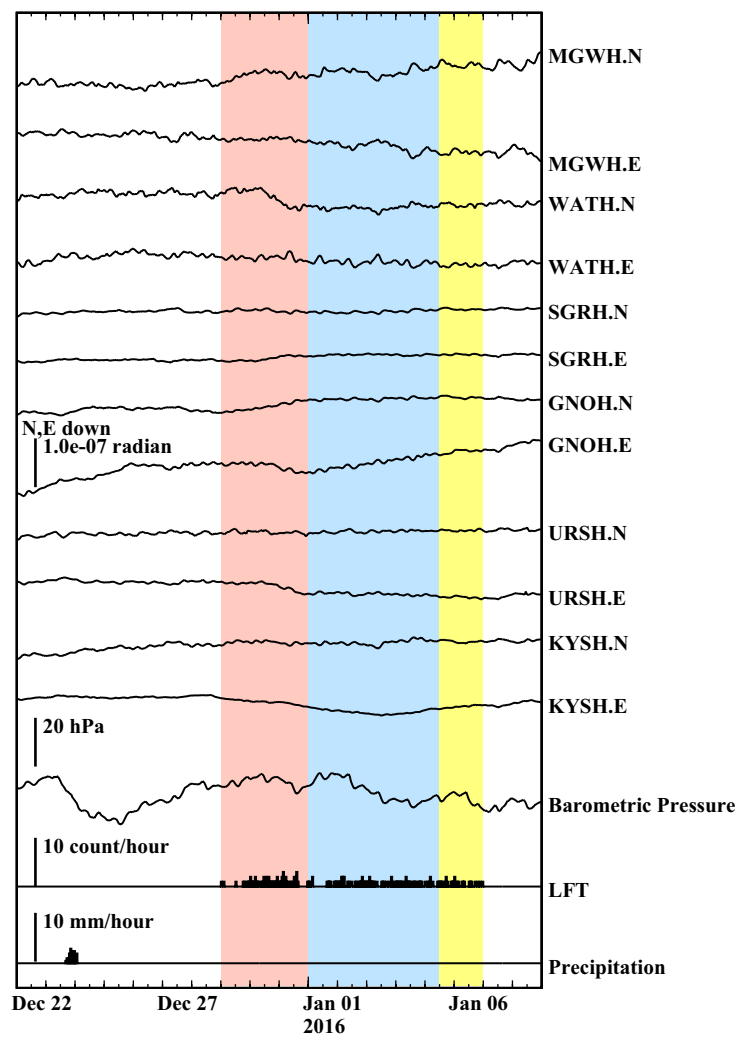

c

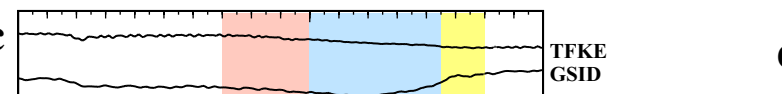

d

b
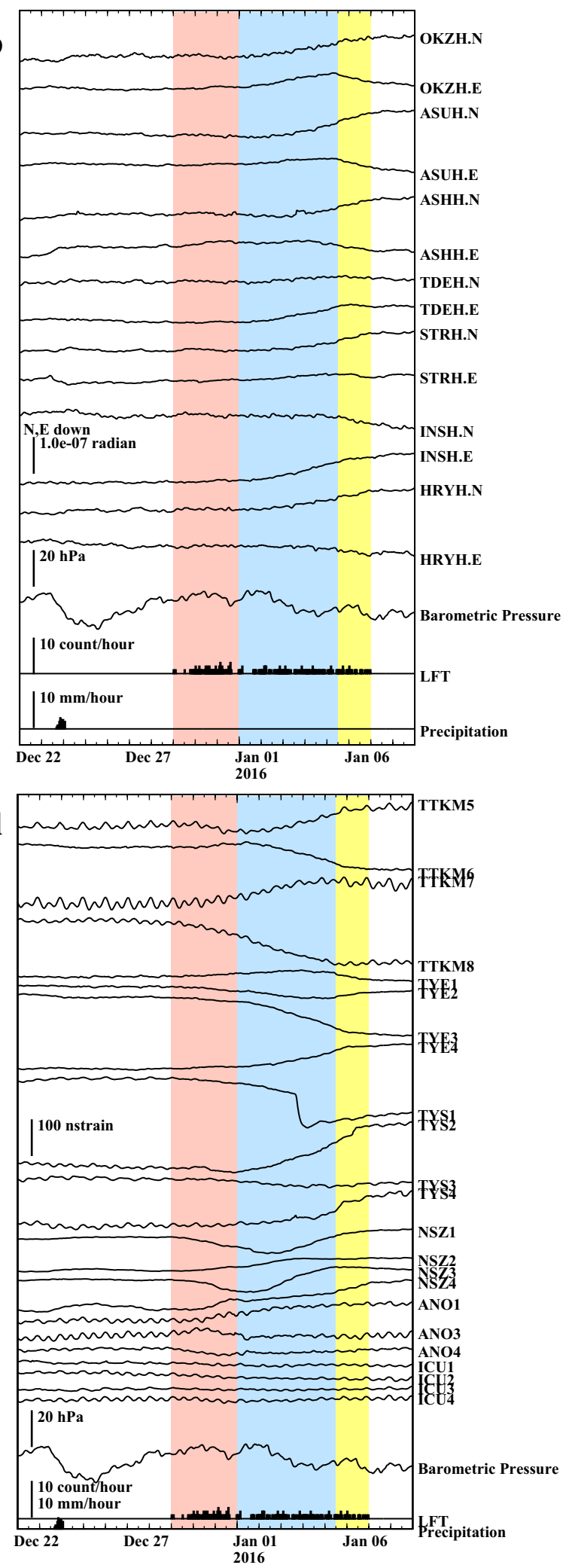

Fig. 11 (See legend on previous page.) 

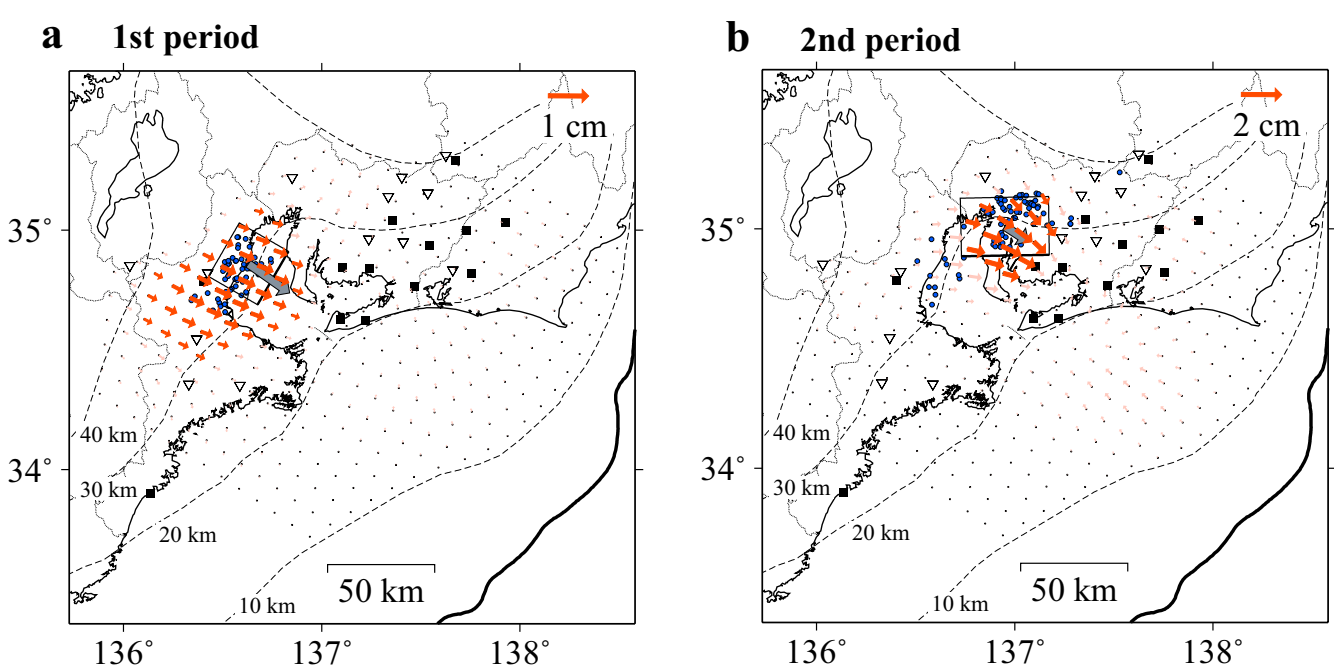

\section{c 3rd period}

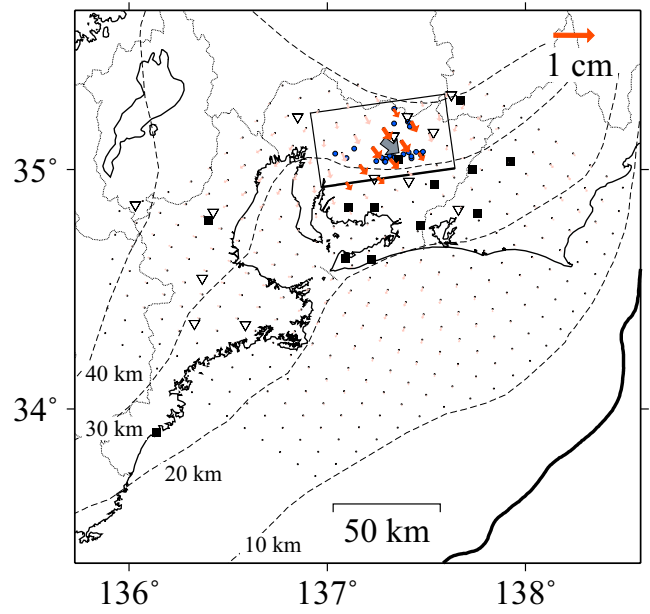

Fig. 12 Estimated slip distributions during 29 December 2015-7 January 2016. Map region corresponds to Area A in Fig. 1. a Surface projection of estimated slip distribution on the plate interface (arrows) and a rectangular fault model (rectangle and gray arrow) for the first period (29 December 2015-1 January 2016). Slips exceeding the standard deviation (10) are shown in red and slips below the $1 \sigma$ are shown in light pink. Colored dots are LFT epicenters in this period (see Fig. 10). The solid line indicates the Nankai Trough and the dashed contours indicate the depth of the Philippine Sea plate. $\mathbf{b}$ Surface projection of estimated slip distribution on the plate interface and a rectangular fault model for the second period ( 1 January to 1200 on 5 January). c Surface projection of estimated slip distribution on the plate interface and a rectangular fault model for the third period (1200 on 5 January-7 January)

strain and tilt data respectively. The optimal hyperparameters are listed in Table 1. Estimated slip distribution, distribution of the standard deviation of the slip in the two orthogonal directions at each subfault, and the comparison between observed strain and tilt data and calculated strain and tilt data are shown in
Figs. 7, 8, 9, respectively. In the comparison between observed strain and calculated strain, linear strain components of each station used for inversion were converted to the principal strain. Seismic moment and the standard deviation and amount of the slip in the

(See figure on next page.)

Fig. 13 Distribution of the standard deviation (10) of the estimated slip (Fig. 12) in the N170E direction (left panel) and N80E direction (right panel) at each subfault. Map region corresponds to Area A in Fig. 1. a, b Standard deviation of the estimated slip for the first period (29 December 2015-1 January 2016). c, d Standard deviation of the estimated slip for the second period (1 January to 1200 on 5 January). e, $\mathbf{f}$ Standard deviation of the estimated slip for the third period (1200 on 5 January-7 January) 


\section{a 1st period N170E slip}

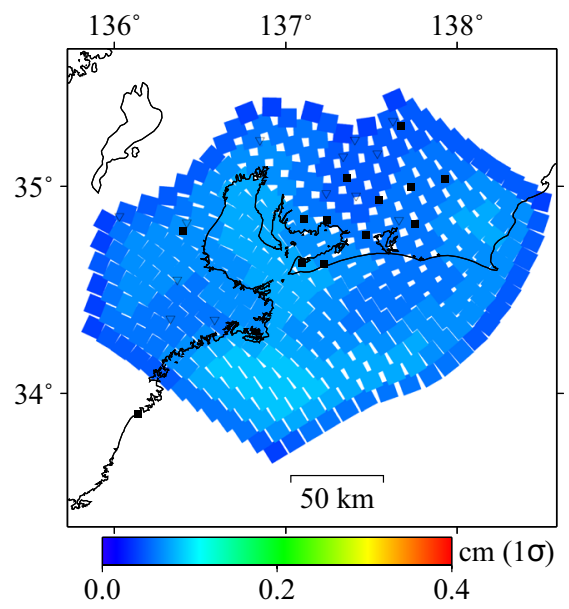

c 2nd period (N170E slip)

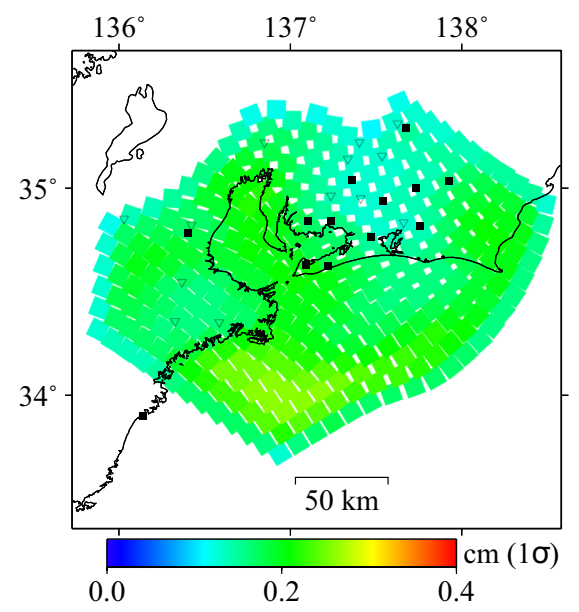

e 3rd period (N170E slip)

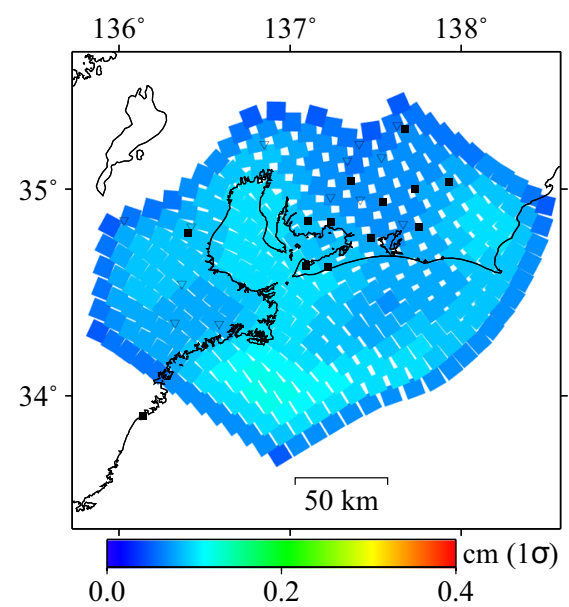

b 1st period N80E slip

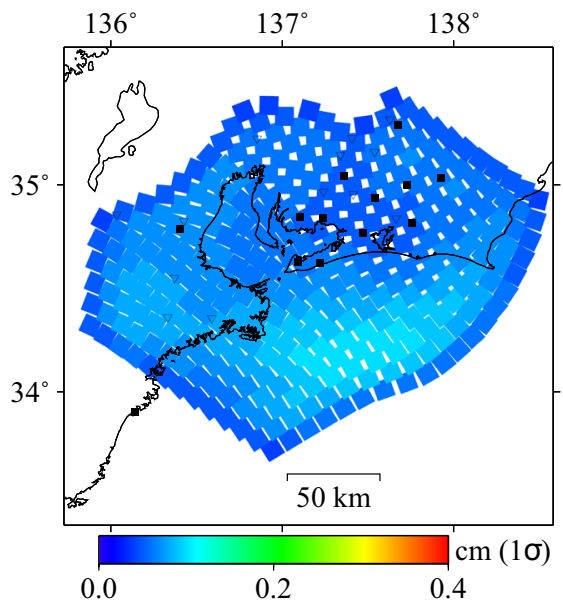

d 2nd period (N80E slip)

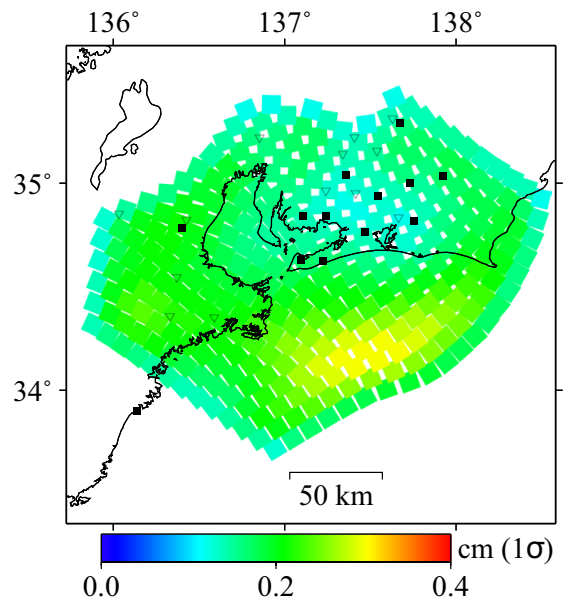

f 3 rd period (N80E slip)

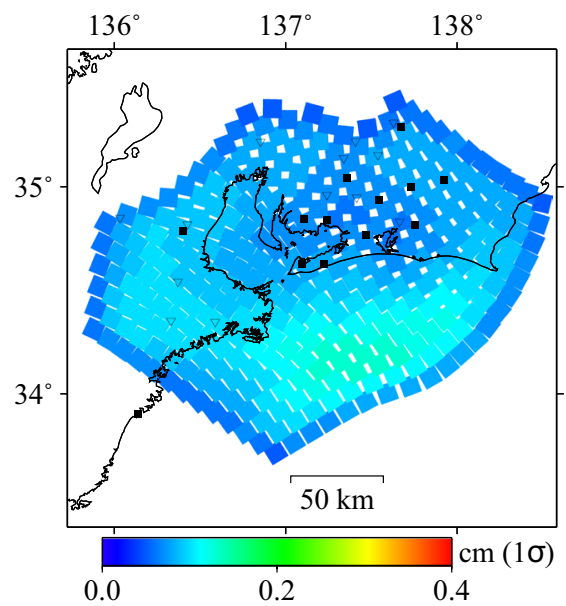

Fig. 13 (See legend on previous page.) 
two orthogonal directions at the maximum slip subfault are listed in Table 2.

The standard deviation ( $1 \sigma$ estimation error) is larger when using stain data or tilt data alone than by joint use (Fig. 8). The ratio of the standard deviation to the estimated slip amount in the two orthogonal directions at the maximum slip subfault are $77 \%$ and $51 \%$ when using strain data alone, while $16 \%$ and $34 \%$ for joint use (Table 2). We could not estimate slip larger than the standard deviation when using tilt data alone (Fig. 7c). Also, when using strain data alone, slips in the same direction as the plate convergence are shown in the eastern side of the grids which are not considered to be due to the short-term SSE (Fig. 7b). The addition of tilt data therefore yielded a more plausible slip distribution with better estimation error.

We denoted the relative weight of strain and tilt data as a value of hyper-parameter $\eta^{2}$. The value of $\eta^{2}$ is 0.38 (Table 1 ) in this example, signifying that the contribution of the strain data was relatively large. Because the average variance ratio of strain and tilt data used in this study was about 0.5 , the ratio obtained by inversion was slightly small.

\section{Example 2}

In the second example, we tested whether the slip distribution can be tracked as a short-term SSE migrates beneath region A in Fig. 2. During 29 December 2015-6 January 2016, LFTs shifted toward the northeast in the Kii Peninsula and the Tokai area (Fig. 10). At the same time, both strain and tilt data change appeared (Fig. 11). These phenomena may correspond to a short-term SSE in this region (e.g., Ochi et al. 2016; Kimura 2016). We divided the data into three periods (Fig. 11) and analyzed slip distributions by our inversion method using strain and tilt data during each period. Observed values and their observation errors are listed in Additional file 1: Table S2. In the variance-covariance matrix, the diagonal elements were set to the ratio of each component's variance to their maximum variance for the strain and tilt data, respectively, from the preceding period (1529 December 2015). The optimal hyper-parameters are listed in Table 1. Estimated slip distribution, distribution of the standard deviation of the slip in the two orthogonal directions at each subfault, and the comparison between observed strain and tilt data and calculated strain and tilt data are shown in Figs. 12, 13, 14, respectively. We also estimated rectangular fault model parameters (rectangle in Fig. 12) with the same dataset. Seismic moment and the standard deviation and amount of the slip in the two orthogonal directions at the maximum slip subfault are listed in Table 2. The slip distribution obtained by inversion follows the propagation of the LFTs and they probably indicate the migration of the short-term SSE. Estimated distribution of slips larger than $1 \sigma$ estimation error is almost same as the distribution of LFTs, whereas the slip distribution of the first period is slightly wide. This may be because there is no observation point on the west side of the slip. The locations of the rectangular faults were generally consistent with the LFTs, but it was estimated to be a bit wider for the third period.

\section{Example 3}

In the third example, we analyzed a short-term SSE that occurred in the Bungo Channel during 23-27 October, 2016 (e.g., Ochi et al. 2017; Kimura 2017) where LFTs were also observed (Fig. 15). Both the strain and tilt data appeared to respond to this event (Fig. 16). We analyzed the slip distribution using strain and tilt data during the period shown in color on Fig. 16 (2100 on 23 October to 0000 on 27 October) and the subfaults of region B in Fig. 2. We also analyzed rectangular fault model parameters using the same data set. Strainmeters are not as densely distributed in this region as in the Tokai region (Fig. 1). Therefore, we also analyzed the slip distributions resulting from the use of strain or tilt data alone and compare the results with the one obtained with joint use. Observed values and their observation errors are listed in Additional file 1: Table S3. The diagonal elements in the variance-covariance matrix were set to the ratio of each component's variance to their maximum variance for the strain and tilt data, respectively, from 10 to 23 October 2016. The optimal

\footnotetext{
(See figure on next page.)

Fig. 14 Observed and calculated strain (right panel) and tilt (left panel) data during 29 December 2015 to 7 January 2016. Map region corresponds to Area A in Fig. 1. a Strain and tilt data for the first period (29 December 2015 to 1 January 2016) from observations (blue) and calculated from the estimated slip distribution shown in Fig. 12a (white). b Strain and tilt data for the second period (1 January to 1200 on 5 January) from observations and calculated from the estimated slip distribution shown in Fig. 12b. c Strain and tilt data for the third period (1200 on 5 January to 7 January) from observations and calculated from the estimated slip distribution shown in Fig. 12C
} 


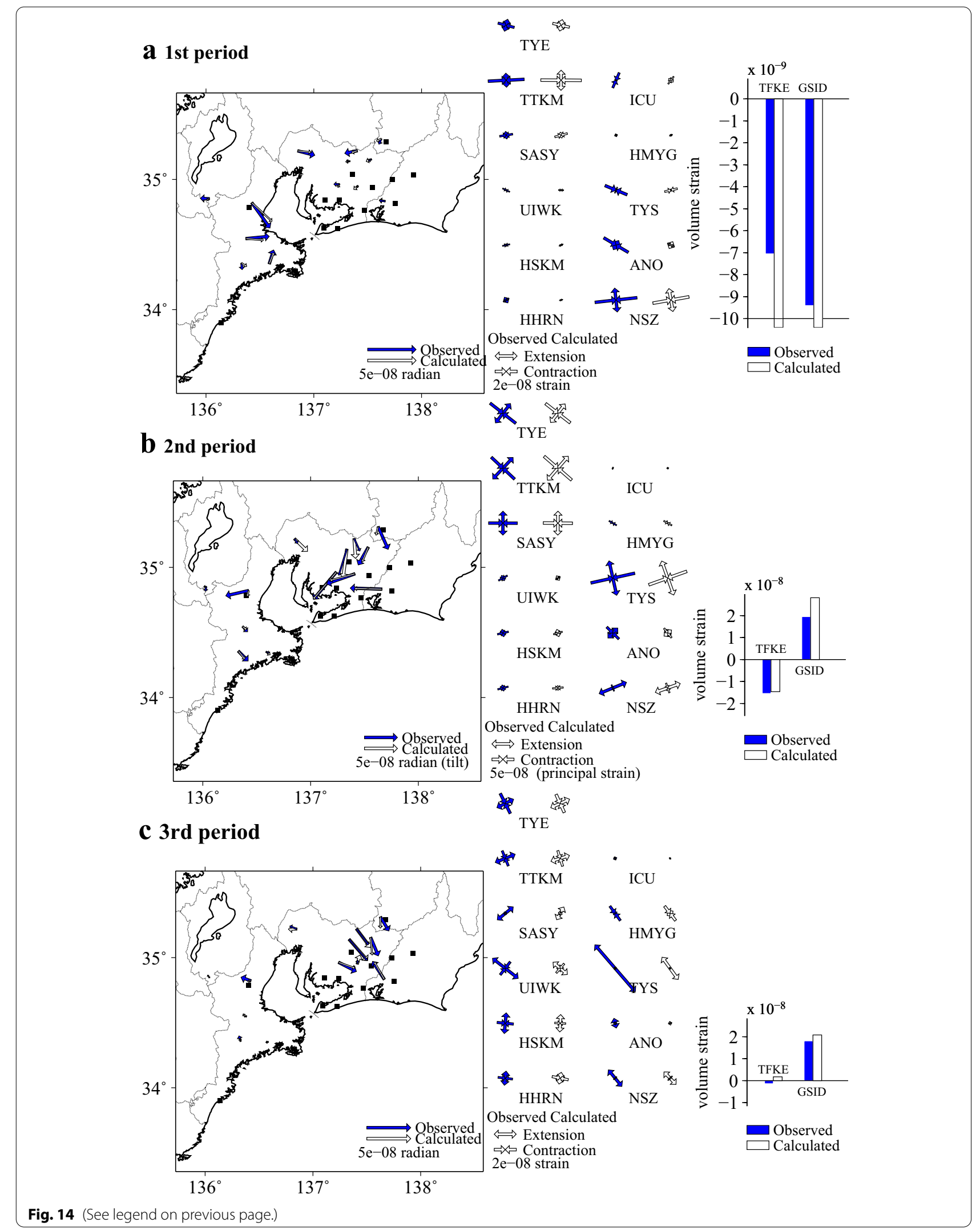




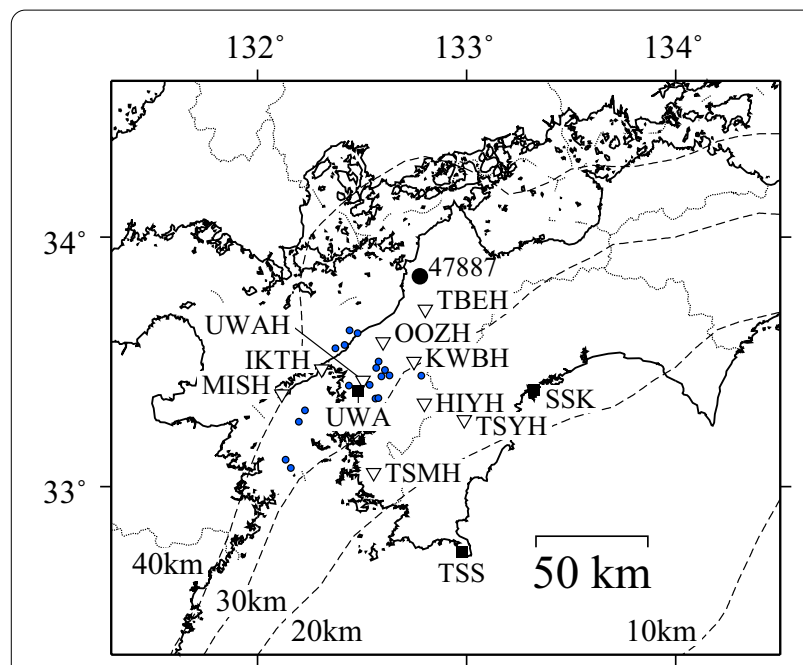

Fig. 15 Epicentral distribution of LFTs (dots) in the Shikoku region during 23-27 October 2016 (NIED catalog). Also shown are locations of strain observation stations (squares), Hi-net (tilt data) stations (triangles), and Matsuyama weather station 47887 (circle). Map region corresponds to Area C in Fig. 1. Dashed contours indicate the depth of the Philippine Sea plate hyper-parameters are listed in Table 1. Estimated slip distribution, distribution of the standard deviation of the slip in the two orthogonal directions at each subfault, and the comparison between observed strain and tilt data and calculated strain and tilt data are shown in Figs. 17, 18, 19, respectively. Seismic moment and the standard deviation and amount of the slip in the two orthogonal directions at the maximum slip subfault are listed in Table 2. Although the standard deviation of the estimated slip is small (Fig. 18) in the result using strain data alone, small slips are widely distributed (Fig. 17b) and there is almost no slip in the distribution of LFTs. When using tilt data alone, we could not estimate slip larger than the standard deviation (Fig. 17c). On the other hand, the standard deviation of each subfault slip estimated by joint use of strain and tilt data is smaller than when using tilt data alone. Region of subfaults where the estimated slip is larger than $1 \sigma$ estimation error is almost the same as the distribution of LFTs (Fig. 17a). In this example as well as Example 1, we could obtain more likely slip distribution by joint use of strain and tilt data.

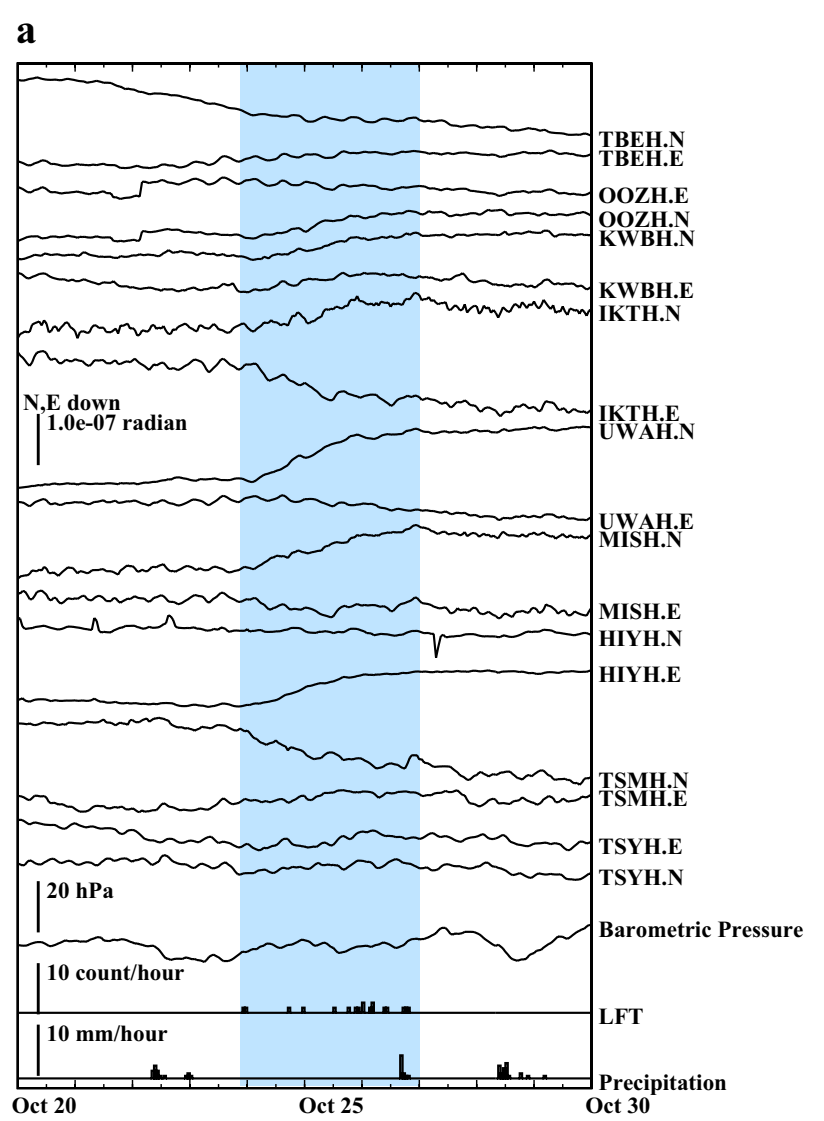

b

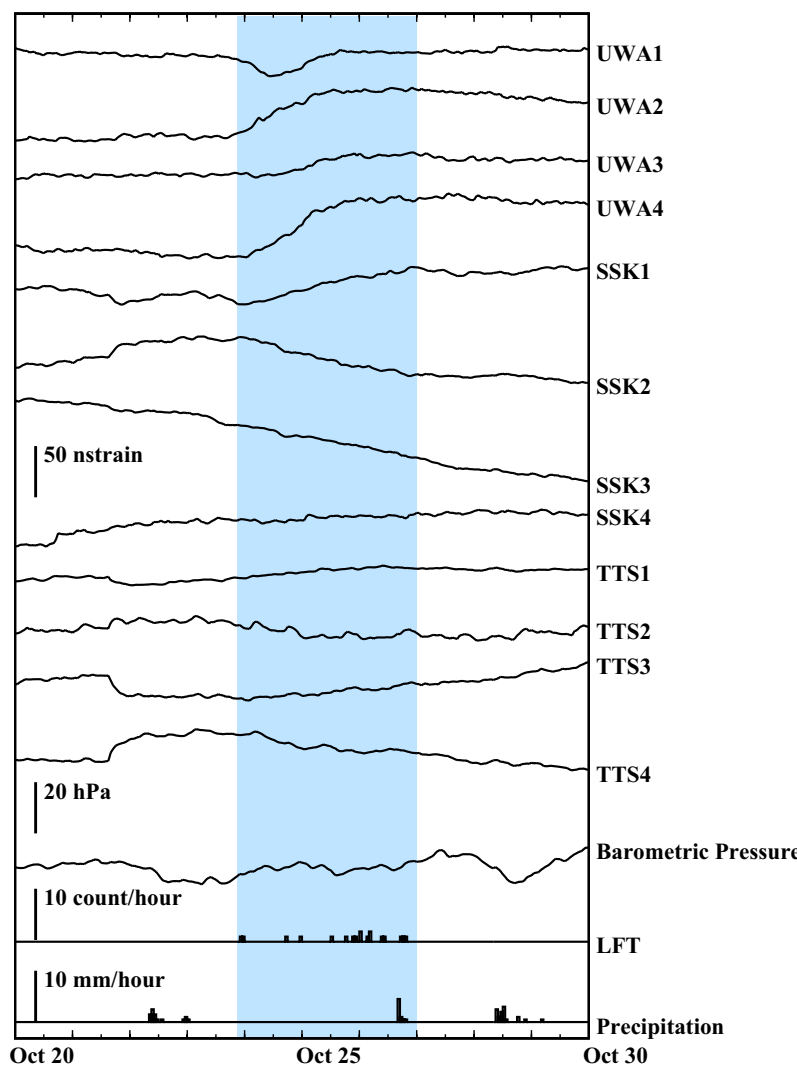

Fig. 16 Time series of $\mathbf{a}$ corrected tilt data and $\mathbf{b}$ corrected strain data for 20-29 October 2016. Also shown are numbers of LFTs per hour and barometric pressure and precipitation data from Matsuyama weather station. Linear trends have been removed from the original strain and tilt data. Data from the period in blue (2100 on 23 October-27 October) were used to estimate slip distributions in this study 


\section{a strain+tilt}

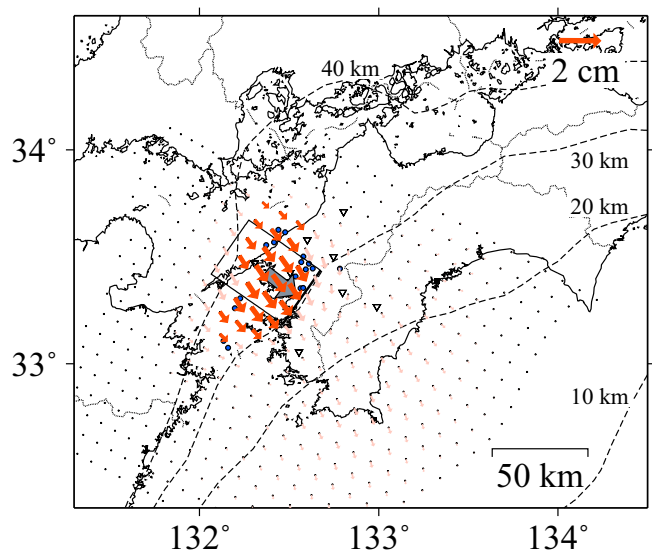

c tilt data alone

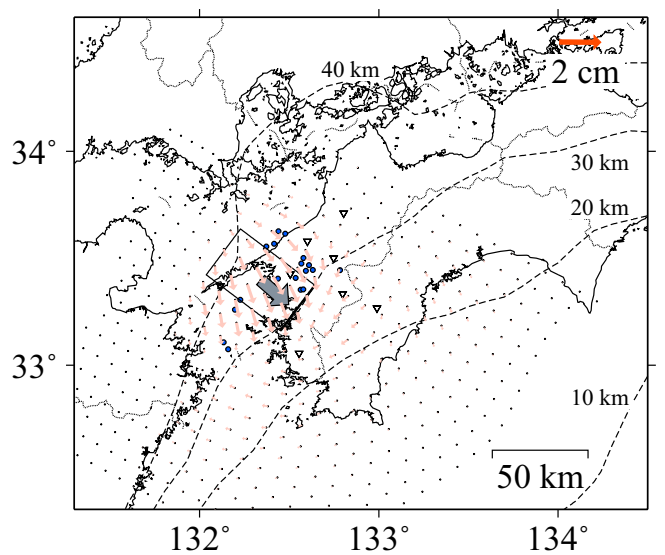

b strain data alone

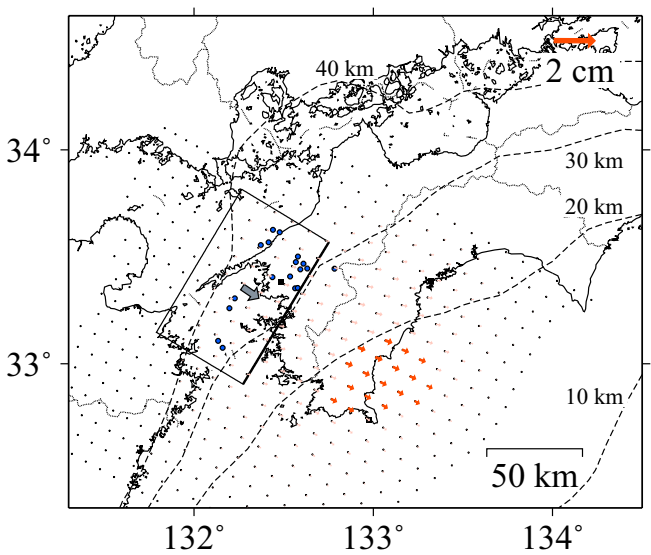

Fig. 17 Estimated slip distribution during 23-27 October 2016. Map region corresponds to Area C in Fig. 1. a Surface projection of the estimated slip distribution on the plate interface (arrows) and rectangular fault model (rectangle and gray arrow) based on strain and tilt data. Slips exceeding the standard deviation $(1 \sigma)$ are shown in red and slips below the $1 \sigma$ are shown in light pink. Colored dots indicate LFT epicenters in this period (see Fig. 15). Dashed contours indicate the depth of the Philippine Sea plate. $\mathbf{b}$ Surface projection of the estimated slip distribution on the plate interface and rectangular fault model based on strain data alone. c Surface projection of the estimated slip distribution on the plate interface and rectangular fault model based on tilt data alone

\section{Conclusion}

Short-term SSEs along the subduction zone of the Nankai Trough are typically detected by interpreting strain and tilt data. We formulated an inversion method to estimate the slip distribution of these SSEs by the joint use of strain and tilt data based on ABIC. The effectiveness of this method was demonstrated by a test using a synthetic dataset. When we applied this method to analyze the slip distributions of known short-term SSEs, we showed that estimated slip distribution follows the migration of the short-term SSE. We also showed that a plausible slip distribution with less estimation error can be obtained by the joint use of strain and tilt data than when each data is used alone. By stochastically evaluating the slip distributions obtained by our method, we showed that it is possible to map variations in the detailed slip distribution on the plate boundary, an improvement over results using rectangular fault models with uniform slip. 


\section{a strain+tilt (N170E slip)}

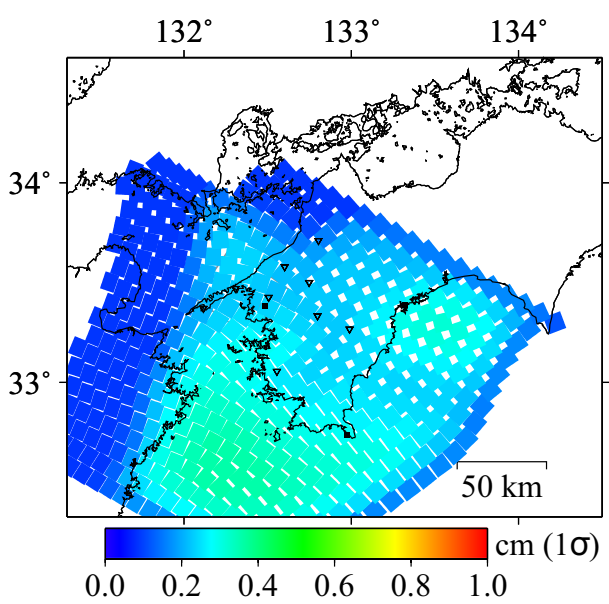

\section{c strain data alone (N170E slip)}

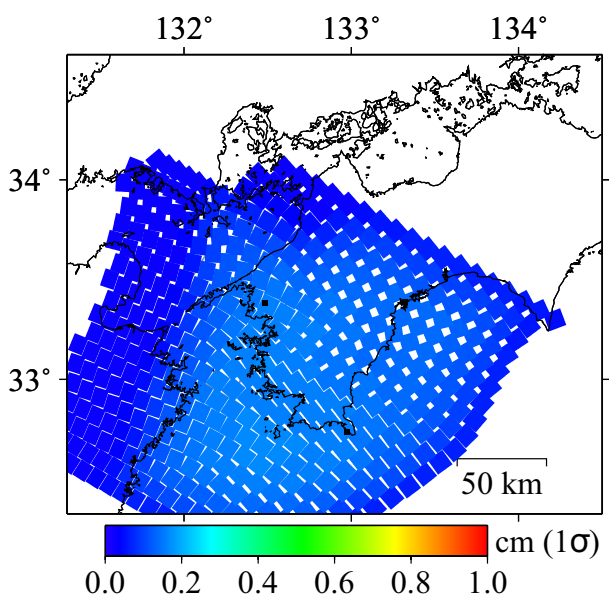

e tilt data alone (N170E slip)

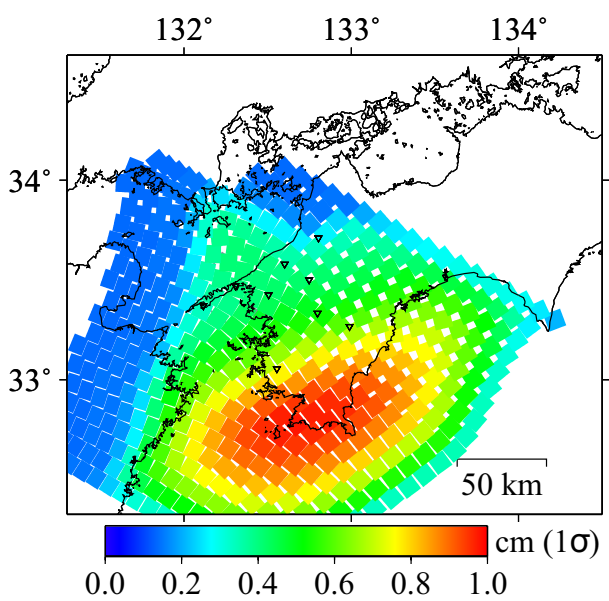

b strain+tilt (N80E slip)

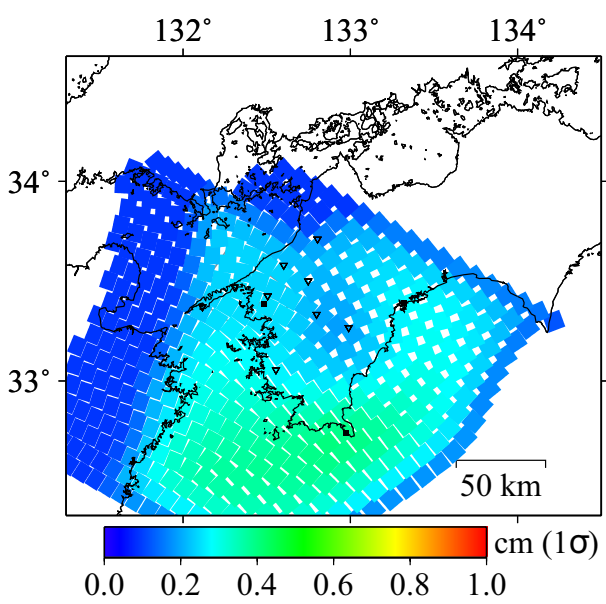

d strain data alone (N80E slip)

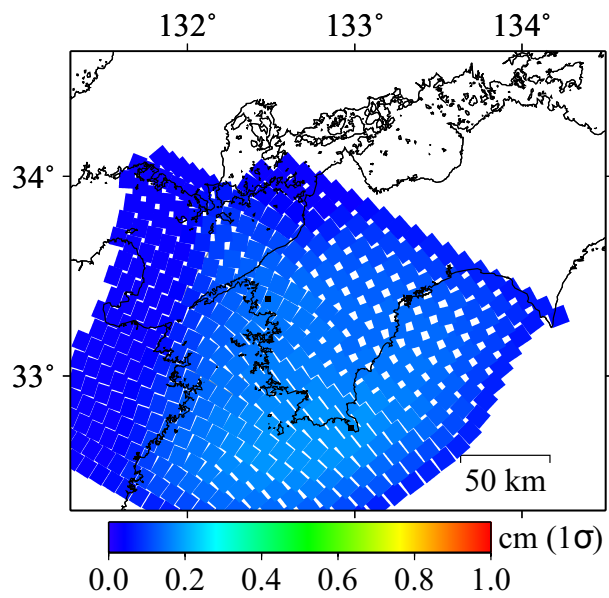

f tilt data alone (N80E slip)

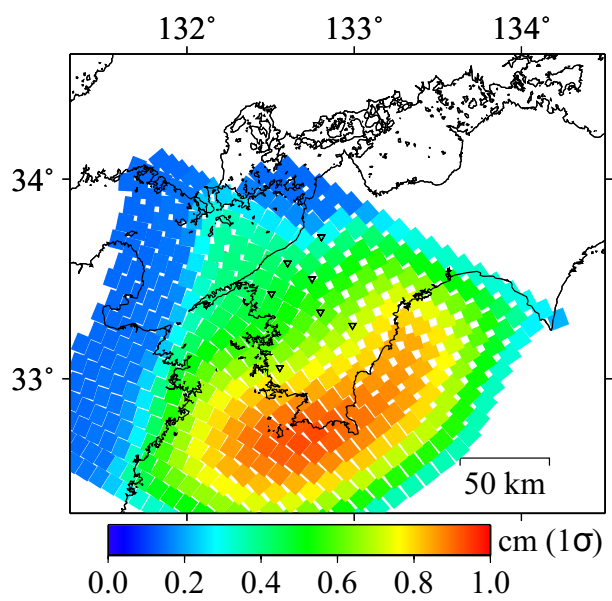

Fig. 18 Distribution of the standard deviation (10) of the estimated slip (Fig. 17) in the N170E direction (left panel) and N80E direction (right panel) at each subfault. Map region corresponds to Area C in Fig. 1. a, b Standard deviation of the estimated slip based on strain and tilt data. c, d Standard deviation of the estimated slip based on strain data alone. $\mathbf{e}, \mathbf{f}$ Standard deviation of the estimated slip based on tilt data alone 


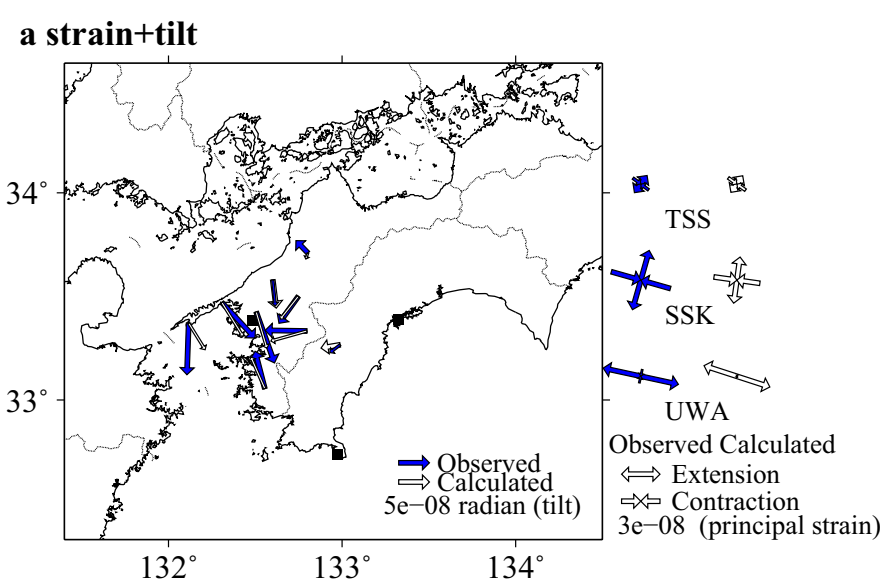

b strain data alone

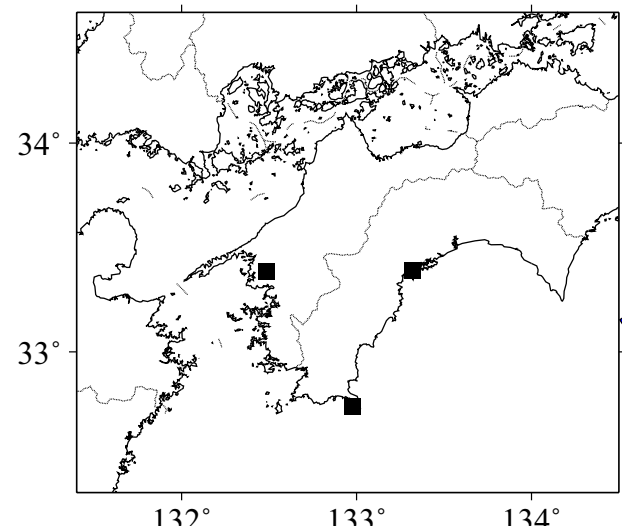

c tilt data alone

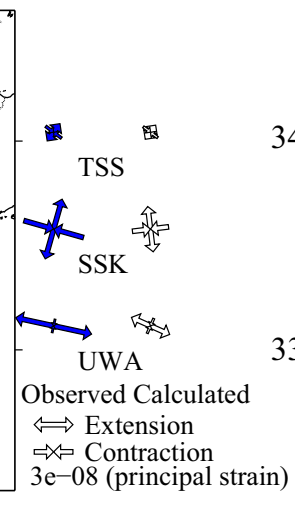

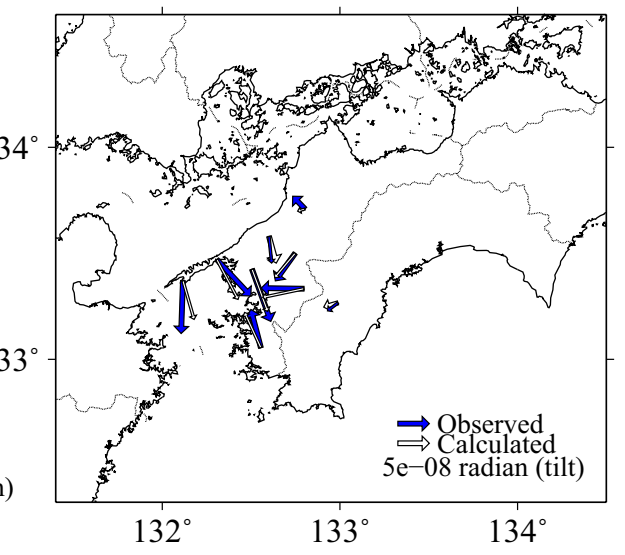

Fig. 19 Observed and calculated strain (right panel) and tilt (left panel) data 23-27 October 2016. Map region corresponds to Area C in Fig. 1. a Strain data and tilt data from observations (blue) and calculated from the estimated slip distribution shown in Fig. 17a (white). b Strain data from observations (blue) and calculated from the estimated slip shown in Fig. 17b (white). c Tilt data from observations (blue) and calculated from the estimated slip distribution shown in Fig. 17c (white)

\section{Abbreviations}

SSE: Slow slip event; GNSS: Global Navigation Satellite System; Mw: Moment magnitude; LFT: Low-frequency tremor.

\section{Supplementary Information}

The online version contains supplementary material available at https://doi. org/10.1186/s40623-021-01517-x.

Additional file 1: Table S1. Observed values during 14-19 April 2015 (Example 1) and their standard deviation during 11 March to 14 April 2015. Table S2. Observed values during 29 December 2015 to 7 January 2016 (Example 2) and their standard deviation during 15-29 December 2015. Table S3. Observed values during 23-27 October 2016 (Example 3) and their standard deviation during 10-23 October 2016.

\section{Acknowledgements}

We thank Akio Katsumata for helpful advice on the manuscript. We used strain data observed by JMA, Shizuoka Prefecture, and AIST. Tilt data were provided by NIED within the framework of collaborative research between MRI and NIED. Hypocenters of low-frequency tremor were taken from the NIED catalog. Generic Mapping Tools software (Wessel and Smith 1998) was used create the figures. We referred to the source code of Yamamoto (2005) to develop software of inversion. We thank two anonymous reviewers and the editor Takuya Nishimura and Aitaro Kato for their careful and constructive reviews.

\section{Authors' contributions}

TT formulated the method, analyzed the data, and wrote the manuscript. AK, TK, and SI discussed the results and revised the manuscript. RK modified the estimation method of rectangular fault model parameters and helped with the preparation of the data. All authors read and approved the final manuscript

\section{Funding}

This work was supported by the Meteorological Research Institute (MRI), Japan Meteorological Agency.

\section{Availability of data and materials}

The datasets used and analyzed during the current study are available from the corresponding author on reasonable request.

\section{Declarations}

Ethics approval and consent to participate

Not applicable. 


\section{Consent for publication}

Not applicable.

\section{Competing interests}

The authors declare that they have no competing interests.

\section{Author details}

${ }^{1}$ Meteorological Research Institute, 1-1 Nagamine, Tsukuba, Ibaraki, Japan.

${ }^{2}$ Japan Meteorological Agency, 3-6-9 Toranomon, Minato, Tokyo, Japan.

${ }^{3}$ National Research Institute for Earth Science and Disaster Resilience, 3-1 Tennodai, Tsukuba, Ibaraki, Japan. ${ }^{4}$ National Institute of Advanced Industrial Science and Technology, 1-1-1 Umezono, Tsukuba, Ibaraki, Japan.

Received: 24 June 2021 Accepted: 8 September 2021

Published online: 26 September 2021

\section{References}

Akaike H (1977) On entropy maximization principle. In: Krishnaiah PR (ed) Applications of statistics, North-Holland, Amsterdam.

Akaike H (1980) Likelihood and the Bayes procedure. In: Bernardo JM, DeGroot $\mathrm{MH}$, Lindley DV, Smith AFM (eds) Bayesian Statistics. University Press, Valencia

Duan Q, Sorooshian S, Gupta V (1992) Effective and efficient global optimization for conceptual rainfall-runoff models. Water Resour Res 28:10151031. https://doi.org/10.1029/91WR02985

Fukuda J, Johnson KM (2008) A fully Bayesian inversion for spatial distribution of fault slip with objective smoothing. Bull Seismol Soc Am 98:11281146. https://doi.org/10.1785/0120070194

Funning GJ, Fukahata Y, Yagi Y, Parsons B (2014) A method for the joint inversion of geodetic and seismic waveform data using ABIC: Application to the 1997 Manyi, Tibet, earthquake. Geophys J Int 196:1564-1579. https:// doi.org/10.1093/gji/ggt406

Gladwin MT, Hart R (1985) Design parameters for borehole strain instrumentation. PAGEOPH 123:59-80. https://doi.org/10.1007/BF00877049

Heki K, Miyazaki S (2001) Plate convergence and long-term crustal deformation in central Japan. Geophys Res Lett 28:2313-2316. https://doi.org/10. 1029/2000GL012537

Hirose H, Kimura T (2020) Slip distributions of short-term slow slip events in Shikoku, southwest Japan, from 2001 to 2019 based on tilt change measurements. J Geophys Res-Solid. 125:e2020JB019601. https://doi.org/ 10.1029/2020JB019601

Hirose H, Obara K (2005) Repeating short- and long-term slow slip events with deep tremor activity around the Bungo channel region, southwest Japan. Earth Planets Space 57:961-972. https://doi.org/10.1186/BF03351875

Hirose F, Nakajima J, Hasegawa A (2008) Three-dimensional seismic velocity structure and configuration of the Philippine Sea slab in southwestern Japan estimated by double-difference tomography. J Geophys Res-Solid 113:B09315. https://doi.org/10.1029/2007JB005274

Hirose F, Maeda K, Kamigaichi O (2019) Tidal forcing of interplate earthquakes along the Tonga-Kermadec Trench. J Geophys Res-Solid 124:1049810521. https://doi.org/10.1029/2019JB018088

Ishii H, Yamaguchi T, Matsumoto S, Hirata Y, Nakao S (2002) Development of multi-component borehole instrument for earthquake prediction study: some observed examples of precursory and co-seismic phenomena relating to earthquake swarms and application of the instrument for rock mechanics. In: Ogasawara H, Yanagidani T, Ando M (eds) Seismogenic process monitoring. Balkema Publishers, Avereest, pp 365-377

Itaba S, Ando R (2011) A slow slip event triggered by teleseismic surface waves. Geophys Res Lett 38:L21306. https://doi.org/10.1029/2011GL0495 93

Itaba S, Kitagawa Y, Koizumi N, Takahashi M, Matsumoto N, Takeda N, Kimura H, Kimura T, Matsuzawa T, Shiomi K (2012) Short-term slow slip events in the Tokai area, the Kii Peninsula and the Shikoku District, Japan (from May to October 2012). Rep Coord Comm Earthq Pred 89:226-238 (in Japanese)

Kano M, Kato A (2020) Detailed spatial slip distribution for short-term slow slip events along the Nankai subduction zone, southwest Japan. J Geophys Res-Solid. 125:e2020JB019613. https://doi.org/10.1029/2020JB019613
Kimura T (2016) Short-term slow slip events with non-volcanic tremor in southwest Japan (November, 2015-April, 2016). Rep Coord Comm Earthq Pred 96:379-382 (in Japanese)

Kimura T (2017) Short-term slow slip events with non-volcanic tremor in southwest Japan (May, 2016-October, 2016). Rep Coord Comm Earthq Pred 97:404-408 (in Japanese)

Kimura T, Kimura H (2015) Short-term slow slip events with non-volcanic tremor in southwest Japan (May-October, 2012). Rep Coord Comm Earthq Pred 89:319-324 (in Japanese)

Kimura K, Tsuyuki T, Suganuma K, Hasegawa H, Misu H, Fujita K (2015) Rainfal correction of volumetric strainmeter data by tank models. Q J Seismol 78:93-158 (in Japanese)

Kobayashi A, Yamamoto T, Nakamura K, Kimura K (2006) Short-term slow slip events detected by the strainmeters in Tokai region in the period from 1984 to 2005. J Seismol Soc Jpn 59:19-27. https://doi.org/10.4294/zisin. 59.19 (in Japanese)

Maeda T, Obara K (2009) Spatio-temporal distribution of seismic energy radiation from low-frequency tremor in western Shikoku, Japan. J. Geophys. Res-Solid. 114:B00A09. https://doi.org/10.1029/2008JB006043

Matsumoto K, Sato T, Takanezawa T, Ooe M (2001) GOTIC2: a program for computation of oceanic tidal loading effect. J Geod Soc Jpn 47:243-248. https://doi.org/10.11366/sokuchi1954.47.243

Miyaoka K (2011) Geomagnetic correction of multi-component strain meters. Q J Seismol 74:29-34 (in Japanese)

Nakanishi I, Kasahara M (1990) Deep earthquake in the Sakhalin, May 12, 1990 observed by array observation of strain seismograph. Seismol. Soc. Jpn. Fall meeting A49 (in Japanese).

Nishimura T, Matsuzawa T, Obara K (2013) Detection of short-term slow slip events along the Nankai Trough, southwest Japan, using GNSS data. J Geophys Res Solid 118:3112-3125. https://doi.org/10.1002/jgrb.50222

Obara K, Kato A (2016) Connecting slow earthquakes to huge earthquakes. Science 353:253-257. https://doi.org/10.1126/science.aaf1512

Obara K, Hirose H, Yamamizu F, Kasahara K (2004) Episodic slow slip events accompanied by non-volcanic tremors in southwest Japan subduction zone. Geophys Res Lett 31:L23602. https://doi.org/10.1029/2004GL0208 48

Obara K, Kasahara K, Hori S, Okada Y (2005) A densely distributed high-sensitivity seismograph network in Japan:Hi-net by National Research Institute for Earth Science and DisasterPrevention. Rev Sci Instrum 76:021301. https://doi.org/10.1063/1.1854197

Obara K, Tanaka S, Maeda T, Matsuzawa T (2010) Depth-dependent activity of non-volcanic tremor in southwest Japan. Geophys Res Lett 37:L13306. https://doi.org/10.1029/2010GL043679

Ochi T, Itaba S, Koizumi N, Takahashi M, Matsumoto N, Kitagawa Y, Takeda N, Kimura H, Kimura T, Matsuzawa T, Shiomi K (2015) Short-term slow slip events in the Tokai area, the Kii Peninsula and the Shikoku District, Japan (from November 2014 to April 2015). Rep Coord Comm Earthq Pred 89:250-261 (in Japanese)

Ochi T, Itaba S, Matsumoto N, Kitagawa Y, Takeda N, Kiguchi T, Kimura H, Kimura T, Matsuzawa T, Shiomi K (2016) Short-term slow slip events in the Tokai area, the Kii Peninsula and the Shikoku District, Japan (from November 2015 to April 2016). Rep Coord Comm Earthq Pred 96:255-270 (in Japanese)

Ochi T, Itaba S, Matsumoto N, Kitagawa Y, Takeda N, Kiguchi T, Kimura H, Kimura T, Matsuzawa T, Shiomi K (2017) Short-term slow slip events in the Tokai area, the Kii Peninsula and the Shikoku District, Japan (from May 2016 to October 2016). Rep Coord Comm Earthq Pred 97:242-253 (in Japanese)

Okada Y (1992) Internal deformation due to shear and tensile faults in a halfspace. Bull Seismol Soc Am 82:1018-1040

Okada Y, Kasahara K, Hori S, Obara K, Sekiguchi S, Fujiwara H, Yamamoto A (2004) Recent progress of seismic observation networks in Japan: Hi-net, F-net, K-NET and KiK-net. Earth Planet Space 56:xv-xxviii. https://doi.org/ $10.1186 / B F 03353076$

Sacks IS, Suyehiro S, Evertson DW, Yamagishi Y (1971) Sacks-Evertson strainmeter, its installation in Japan and some preliminary results concerning strain steps. Pap Meteorol GeoPhys 22:195-208. https://doi.org/10.2467/ mripapers1950.22.3-4_195

Tamura Y, Sato T, Ooe M, Ishiguro M (1991) A procedure for tidal analysis with a Bayesian information criterion. Geophys J Int 104:507-516. https://doi. org/10.1111/j.1365-246X.1991.tb05697.x 
Wessel P, Smith WHF (1998) New, improved version of the Generic Mapping Tools released. EOS Trans Am Geophys Union 79:579. https://doi.org/10 1029/98EO00426

Yabuki T, Matsu'ura M (1992) Geodetic data inversion using a Bayesian information criterion for spatial distribution of fault slip. Geophys J Int 109:363-375. https://doi.org/10.1111/j.1365-246X.1992.tb00102.x

Yamamoto T (2005) Development of a software to assist crustal deformation analysis. Tech Rep Meteorol Res Inst 46:156-159. https://doi.org/10.

11483/mritechrepo.46 (in Japanese)

\section{Publisher's Note}

Springer Nature remains neutral with regard to jurisdictional claims in published maps and institutional affiliations. 